\title{
Does price-cap regulation work for increasing access to contraceptives? Aggregate- and pharmacy-level evidence from Colombia *
}

\author{
Tatiana Andia $^{\dagger} \quad$ César Mantilla $^{\ddagger} \quad$ Álvaro Morales ${ }^{\S} \quad$ Santiago Ortiz \\ Paul Rodríguez-Lesmes"
}

October 19, 2020

\begin{abstract}
Background: Price caps through international reference pricing are widely used around the World, but not so commonly in over-the-counter markets (OTC). We study this type of regulation for the case of oral contraceptives in Colombia, which is a de facto OTC market.

Objectives: We aim to establish whether the regulation triggered a competitive response within and across product categories (active pharmaceutical ingredients). We also study whether regulated products targeted to customers from high socio-economic status are now distributed in pharmacies from low socio-economic neighborhoods.

Methods: First, we use a fixed effects linear panel model to estimate the change in prices and quantities associated with the new regulation for regulated and non-regulated products using administrative data at the wholesale level, according to three price tiers. Second, we conducted an audit study with 213 community pharmacies in the city of Bogotá, Colombia. We visited pharmacies twice, before and after the introduction of the price cap, collecting information on prices and availability of six selected brands.

Findings: The wholesale-level analysis reveals a price reduction in regulated and nonregulated products with a regulated active ingredient. Traded quantities increase for the same product types, but only for those in the most expensive categories. Besides, the traded quantities of non-regulated products decrease. Although this price reduction is also transmitted
\end{abstract}

${ }^{*}$ We would like to thank the members of Salud Visible (Universidad de los Andes), Universities Allied for Essential Medicines (Universidad Nacional), and Jóvenes Investigadores team from Universidad del Rosario for taking part as simulated clients: Juan Pablo Baquero, Emilia Cárdenas, Liliana Cortés, Nicolas Currea, Sara Delgado, María Camila Díaz, Diana Jany, Karen Liseth Franco, Daniela González, Christian Leal, Daniela López, Kevin López, Luisa Medieta, Valentina Muñoz Bernal, Elsy Ramírez, Gustavo Rojano, Steffanny Romero, Juliana Sánchez, Andrea Juliana Silva, Pablo Toro, Jhonathan Vanegas, Maria Gabriela Vargas, Juan Pablo Vega, Santiago Villanueva, and Juan Diego Zapata. Financial Support from the programs "Inclusión productiva y social: programas y políticas para la promoción de una economía formal, código 60185, que conforma la Alianza EFI, bajo el Contrato de Recuperación Contingente No. FP44842-2202018." and "Universidad del Rosario, Fondo de Arranque: Economía de la salud, temas en política farmacéutica" are gratefully acknowledged.

†Facultad de Ciencias Sociales, Universidad de los Andes. e-mail: tandia@uniandes.edu.co

${ }_{\ddagger}^{\ddagger}$ Economics Department, Universidad del Rosario. e-mail: cesar.mantilla@urosario.edu.co

$\S$ Colombian Ministry of Health. e-mail: alvaro0126@gmail.com

『Economics Department, Universidad del Rosario. e-mail: santiago.ortizo@urosario.edu.co

\|Economics Department, Universidad del Rosario. Corresponding author. e-mail: paul.rodriguez@urosario.edu.co 
to community pharmacies, the availability of the high-end and mid-range contraceptives included in our audit study decreases as well. We provide suggestive evidence that reduction in the availability of was larger in areas of low socio-economic status.

Conclusions: Price cap regulations that might look as effective in lowering prices and expanding access at the aggregate level could conceal stocking patterns that negatively affect the product availability for the final consumer.

JEL Codes: I110, I150, I180

Keywords: pharmacies, pharmaceuticals, drugs, simulated clients, contraceptive pills

\section{Introduction}

Several Latin American countries are among the leaders in teenage pregnancy rates in the World, and one of the determinants is the lack of access to safe contraceptive methods (Pan American Health Organization et al. 2016; United Nations, 2020). Despite the interventions at the school level on sexual and reproductive health, the final determinant is the affordability of promoted methods (World Health Organization, 2011; UNESCO, 2017). Price caps to leading contraceptive products constitute an appealing policy instrument to tackle affordability (World Health Organization, 2015). However, this instrument might backfire: in the short-term, controlled prices could result in a lower supply of products and a potential decrease in their availability. In the long-term, the decision to release new generations of these products might result distorted (Costa-Font et al. 2014). In this paper, we study the immediate consequences on the accessibility of a pharmaceutical price regulation in Colombia, directed to contraceptives, which drove down prices of regulated products by an average of 61\% (Ministerio de Salud y Protección Social, 2019).

Since 2012, a cornerstone policy in Colombia for containing health expenditures is to set maximum prices based on the price paid for the same products in other countries (Sood et al., 2008; Von der Schulenburg et al., 2011; Acosta et al., 2014; Prada et al., 2018). This policy was initially directed to highly concentrated markets, where few laboratories control expensive medications for rare or high-cost diseases, largely affecting the health insurance (HI hereafter) budget ${ }_{1}^{1}$

In 2018, the National Medicines Pricing Commission decided to implement this policy in the contraceptive market, which is mostly private, with very few products included in the basic healthcare plan. The argument was that, while they were not a threat to the government budget, contraceptives were relevant for out-of-pocket expenditures. The policy applies to a reduced set of products that could be found in the reference countries, and for which there was a high concentration at the active principle level. The Circular 07/2018 regulated 58 product presentations, including 47 oral contraceptives, nine emergency contraceptives, and two implants. $\left.\right|^{2}$ Months later,

\footnotetext{
${ }^{1}$ Some examples of these medications are Adempas (Bayer), for treating certain forms of pulmonary hypertension in adults; Avastin (Roche), for treating wet age-related macular degeneration (AMD), diabetic eye disease and other retinal problems; and Mabthera (Roche), for treating rheumatoid arthritis.

${ }^{2}$ The methodology used for the application of direct price control regime for medicines was published in Circular 03/2013. According to this document, a relevant market is defined as the set of drugs that compete with each other, which have identical compositions, doses and similar formulas. A relevant highly concentrated market is one whose number of competitors is at most three, or whose $\mathrm{HHI}$ is greater than 2,500. Drugs from the relevant high concentration
} 
the Circular 09/2019 regulated another two contraceptives.

Let us give a glimpse of the reach of these regulations. During the Fourth Quarter of 2018, $56 \%$ of all the sold oral contraceptives corresponded to regulated units, and their value share was $71 \% \sqrt[3]{3}$ These numbers give an idea about the effects of the price cap over large operations between laboratories and distributors, which have to record every transaction in a governmental information system. However, the transactions below this level, including final consumer purchases, are neither audited nor reported in this system. An open empirical question is how community pharmacies reacted to this top-down regulation. The relevance of understanding this "cascade" effect dwells on $80 \%$ of the contraceptive sales in Colombia occurring through the commercial market (Ministerio de Salud y Protección Social, 2019).

Contraceptives from past generations are included in the Colombian universal health benefits package, and they could be obtained almost free of charge with a prescription under the mandatory HI. In addition to the fact that contraceptives prescribed by physicians are from newer generations, three reasons explain the prevalence of the commercial channel: bureaucracy costs (prescriptions usually must be requested every month), moral costs (e.g., fear of feeling ashamed by physicians), and transaction costs (e.g., attending a specific institutional pharmacy for delivery). Community pharmacies reduce these costs: they are available in every neighborhood and, though required, they rarely ask for prescriptions (Vacca et al., 2011; Andia et al., 2020). Thus, for contraceptive products, despite having a low out-of-pocket expenditure level (Guerrero et al., 2015), individuals face open market prices in a standard over-the-counter (OTC) market without any reimbursement.

We use a model of vertical differentiation as a framework for analyzing price sensitivity in the contraceptives market, assuming that customers are divided between loyal and non-loyal for the targeting of branded products (Frank and Salkever, 1992). As in Wiggins and Maness (2004), branded generics are competing for loyal customers. In this setup, external price referencing has ambiguous impacts on firms' competition in pharmaceutical markets with loyal customers (Brekke et al., 2016). The vertical differentiation framework results accentuated in the contraceptives market, given the marketing strength of laboratories and the safety and adverse effects of the active ingredients. By the time of the regulation, products including fourth-generation active ingredients, the latest standard, were the most expensive available products ${ }^{4}$

With this context in mind, we introduce in detail our question and the two exercises we performed to tackle it. We want to understand whether the price cap regulation on contraceptives, applying for a subset of the market products, improved access to formerly expensive contraceptives for individuals from low socio-economic status (SES hereafter). In our first exercise, we exploit the aggregate administrative data. We estimate how price and quantities for regulated

markets will be incorporated into the direct control regime when the sale price observed in the national market, in the respective commercial presentation, is above the International Reference Price (IRP).

${ }^{3}$ For this calculation, we employed the set of oral contraceptives from the laboratory's commercial channel having transaction reports every quarter, with registered transactions since 2017Q1. Hereafter, we will use this format when referring to specific year-quarter information. We excluded the reported drug samples.

${ }^{4}$ The market classifies oral contraceptives into "generations" (Bitzer. 2015), introducing new progestins aimed at reducing adverse effects such as acne, oily skin, hair growth, and venous thrombosis (Sitruk-Ware et al. 2012). Fourthgeneration contraceptives, the more recent to the date of this study, are compound by Dienogest or Drospirenone. 
and non-regulated products, from different price categories, are affected by the regulation. We do so by fitting linear panel models over time series of average prices and traded quantities at the wholesale level of the products' presentations available in the market.

We find a price reduction for two types of products: regulated products and non-regulated products that are direct competitors because they share an active ingredient. For brevity, throughout the rest of this paper, we will refer to the latter product type as having a "regulated-ingredient." By contrast, products in which no active ingredient was regulated do not change their price. This result suggests that, at least at the wholesale level, the relevant market is defined by the active ingredient, despite the potential therapeutical substitutability of all oral contraceptives. We also observe a massive expansion of regulated products' sales and a relevant reduction of sales in nonregulated drugs.

Our analysis at the wholesale level does not let us disentangle the stocking pattern of distributors from an actual expansion of the contraceptive market, particularly for the latest generation of contraceptives. This is why, in our second exercise, we explore the effects of this regulation on the demand-side by employing the simulated client methodology (SCM hereafter). We conduct an audit study in which we ask about the price and availability of six brands of oral contraceptive pills, including two different active components and three price levels, in community pharmacies in Bogotá. ${ }^{5}$

The SCM, also known as the "audit study technique" 6 has been employed in the Health Economics domain to study abuse of antibiotic prescriptions (Currie et al. 2011: Smith, 2009; Wafula et al., 2012; Miller and Goodman, 2016), providers' selection of health plans based on geographic cues (Bauhoff, 2012), and differences among private and public health care providers (Das et al. 2016). In Colombia, the use of the SCM revealed that $80 \%$ of the sampled pharmacies do not request a prescription for delivering antibiotics (Vacca et al. 2011). The SCM is particularly useful in low- and middle-income countries (LMICs) characterized by low monitoring capacity and the low quality of administrative data sources (Madden et al., 1997; Watson et al., 2006; Das et al., 2018; Kwan et al., 2019). In our case, the SCM allows us to conduct audit visits in community pharmacies, before and after the regulation, to understand better the impacts of the price-cap at a more disaggregated level. In our study, simulated clients ask for the products and their respective prices, as if they were willing to purchase the product for their younger sister. We covered 213 community pharmacies located around a city of 8 million inhabitants, with substantial income inequality, and nearly 3,000 community pharmacies..$^{7}$

Our results indicate that, although the price reductions were transmitted to the final consumer, these were accompanied by a reduction in the high-end and mid-range regulated product's availability. Moreover, we do not observe the desired expansion of high-end and mid-range regulated contraceptives to low SES areas. If anything, we observe a more pronounced decrease in availability in these areas.

\footnotetext{
${ }^{5}$ In the Fourth Quarter of 2018, the selected oral contraceptives represented $31.64 \%$ of total sales value and $15.29 \%$ of sold units in the transactions between laboratories and commercial distributors.

${ }^{6} \mathrm{An}$ audit study is defined as a technique controlling personal contact of testers on one side of the market, with those naturally trading on the other side of the market (List. 2004).

${ }^{7}$ https://www .portafolio.co/negocios/empresas/colombia-locales-comerciales-son-droguerias-45412
} 
This paper contributes to the literature on two fronts. First, our short-term analysis is useful to study changes in the availability of the regulated product, which is of particular interest for contraceptives given its distribution throughout an OTC market and its potential impact on contraception. Most of the existing analyses of the effects of pharmaceutical price regulations focus on medium- and long-term effects. For instance, on the modification to the competitive structure of the market given the exit of some products (Zhang et al., 2016), and on the distortion of intertemporal decisions of manufacturers to release new products (Brekke et al., 2016). Our second contribution is the combination of statistical analyses at two different scales and how their incongruence sheds light on stocking patterns that would have remained concealed by using data only at the wholesale or pharmacy level.

The remainder of this paper is organized as follows. In Section 2 we explain or methodological approaches for analyzing the data at the wholesale level, and for collecting and analyzing the data at the pharmacy level. Section 3 presents the main results, which are discussed in Section 4 . Section 5 concludes.

\section{Methods}

\subsection{Use of administrative data at the wholesale level}

\subsubsection{Data sources}

First, we use the Colombian drug price information system -SISMED, for its acronym in Spanish. SISMED is a source of non-reserved information on the prices and sales of drugs sold across the market through the commercial and the institutional channels. We use quarterly data for the periods between 2017Q1 to 2019Q3 for the commercial channel, accruing at least eighty percent of all the sales.

Second, we use the drug registry maintained by INVIMA for the Colombian pharmaceutical market. This database provides information about each drug presentation licensed in Colombia, characterized by its unique drug code or CUM, for its acronym in Spanish. Drug presentation is defined as a unique combination of the drug name, dosage, and commercial description.

For contraceptives, this registry also includes information about the brand name, which can be associated with more than one CUM; its manufacturing laboratory; its regulation status (i.e., regulated or not); its route of administration (i.e., oral, injectable, emergency and patch contraceptives); and its commercial status (i.e., medical sample or common drug). To June 2019, there were 749 active CUM: 492 oral contraceptives, 132 patches/implants/injections contraceptives, and 125 emergency contraceptives.

\subsubsection{Selection and classification of contraceptives for the analysis}

There are 79 product presentations, registered within the relevant ATC classification codes, for which there is at least one transaction since 2017Q1. We limit the analysis to those products for

\footnotetext{
${ }^{8}$ This is the Colombian National Institute of Food and Drug Safety.
} 
which there was at least one registered transaction every year between 2017Q1 and 2019Q3, for a final sample of 52 product presentations. The purpose of this selection rule is to properly understand the price dynamics associated with the regulation. The characteristics of this restricted sample products are reported in Table 1. while the characteristics of the non-restricted sample are available in Table A1 (see Appendix).

We classified the contraceptives on three price categories, based on the distribution of prices before the regulation: Bottom $(<18,000$ COP), Intermediate $(18,000-49,000$ COP) and Top $(>$ 49,000 COP) 9 This distribution is displayed in Figure A1 (see Appendix). The choice of these price ranges allows us to connect our two exercises. For the audit study, explained in detail in Section 2.2. we select six contraceptives. The two low-end brands belong to the Intermediate price category and they are used to define a benchmark price. The average price of all products in the Intermediate category is virtually identical to the average price of these two low-end brands, as is shown in Table 1. This definition of a benchmark price allows us to use the same numerary in both statistical analyses 10

Table 1 reports some market-related characteristics of the selected products, by price range. This classification allows us to identify four patterns before the regulation period (2018Q4) ${ }^{11}$ First, price differences are considerable across categories. The ratio of average prices between the Top and Bottom price categories is almost $5{ }^{12}$ Second, fourth-generation contraceptives are absent from the Bottom price category, while they account for about half and two-thirds of products in the Intermediate and Top price categories, respectively. This pattern reveals that part of the vertical differentiation in this market is based on objective quality. On the other hand, products in the Bottom category have been active in the market for a longer period. The same pattern applies when comparing the Intermediate and Top price categories. Third, the Bottom category accounts for $47.5 \%$ of the market units despite having only $21.1 \%$ of the brands. Moreover, the Intermediate category is the most competitive according to the computation of the Herfindahl-Hirschman Index - HHI for each price range. Fourth, in terms of regulated units and regulated sales value, the Top price category was affected with higher intensity by the price-cap regulation.

\subsubsection{Empirical strategy}

We formally analyze changes in prices and quantities after the regulation for the 52 product presentations with two linear panel fixed effects specifications. Equation 1 considers mean differences

\footnotetext{
${ }^{9}$ The average exchange rate was on average 3,300 COP/USD. Purchasing power parity conversion factor is $1,326.8$ (2018) and 1,349 (2019).

${ }^{10}$ Table A2 (see Appendix) reveals that the regression results are robust to three alternative configurations of the thresholds defining the price categories: (i) increasing the lower limit to the Intermediate category to $28,000 \mathrm{COP}$ and $22,000 \mathrm{COP}$, with these two values obeying to "natural" modes in the distribution of prices; and (ii) adjusting the upper limit of the first and second tertile of the distribution of prices before the regulation (Bottom $(<21,000 \mathrm{COP})$, Intermediate $(21,000-47,000$ COP) and Top (>47,000 COP)).

${ }^{11}$ The sample has contraceptives that reported data at least once every year, and therefore, we do not have data for all medications in all periods. For this reason, as a period of reference, we use 2018Q4 given that this period had reports of all 52 contraceptives.

${ }^{12}$ Note that we define a "benchmark price," connecting our two exercises. This benchmark is the average price of two specific products, Dienille and Drospera, employed in our audit experiment.
} 
Table 1: Characteristics of products within price ranges before the regulation - 2018Q4

\begin{tabular}{lrrr}
\hline \multirow{2}{*}{ \# Products (CUM): 52} & \#ATC: 15 & \multicolumn{3}{c}{ Price Categories } \\
\cline { 2 - 4 } & $\begin{array}{c}\text { Bottom } \\
\text { Intermediate }\end{array}$ & \multicolumn{1}{c}{ Top } \\
& $\leq 18,000$ & $(18,000 ; 49,000]$ & $>49,000$ \\
\hline Commercial description (Brands) & $11 / 52$ & $29 / 52$ & $12 / 52$ \\
Active ingredients (ATC code) & 5 & 12 & 5 \\
Laboratories & 9 & 9 & 5 \\
Average price (USD) & 3.41 & 9.98 & 17.39 \\
Average price with respect to benchmark & 0.26 & 0.78 & 1.37 \\
Fourth generation (\%) & 0 & 55.17 & 75 \\
Quarters since the product started to be active & 42.9 & 34.86 & 33.3 \\
Quarters since the register was issued & 61.4 & 47.5 & 39.1 \\
Market share units (\%) & 47.51 & 31.35 & 21.12 \\
Market share sales value (\%) & 16.34 & 38.20 & 45.44 \\
HHI & 2421.09 & 1906.84 & 3876.95 \\
HHI sales value & 2080.61 & 2015.52 & 3844.52 \\
Regulated brands (\%) & 27.2 & 51.7 & 50 \\
Regulated units (\%) & 28.10 & 76.84 & 86.07 \\
Regulated sales value (\%) & 28.17 & 72.98 & 84.97 \\
\hline
\end{tabular}

Notes: Calculations based on administrative data records from SISMED including all oral contraceptives with registered transactions at least every year (2017-2019). For this analysis, we used data from 2018Q4, the last period before the regulation. In the computations of the Herfindahl-Hirschman Index (HHI) we assumed three markets, one per price level. We aggregated sales and sales values by manufacturer (laboratory) in each market. Quarters Active and Quarters Issued are the average difference between the active and issued date, with respect to 2019Q1. Benchmark value is $41,908 \mathrm{COP}$, corresponding to US\$12.69 according to an average exchange rate of 3,300 COP/USD between 2018Q4 and 2019Q1. The benchmark value corresponds to the average price of low-end audited brands (Dienille and Drospera) before regulation. Products are defined by their unique combination of the drug name, dosage, and presentation (CUM code).

per price category. When the outcomes of interest are prices, $Y_{i t}$ corresponds to the average price per unit of the product presentation $i$ in quarter $t$ as relative to the benchmark value described above. When the outcome of interest are quantities, $Y_{i t}$ corresponds to the logarithm of the total sold units of $i$ in $t$.

As for the regressors, $P C_{j i}$ is a categorical variable capturing the price category $j$ of product $i$ (i.e., $j=1$ for Bottom, $j=2$ for Intermediate, and $j=3$ for Top). The period after the regulation is indicated by the binary variable $A_{t}$, which takes the value of 1 from 2019Q1 onwards. The equation also includes quarter dummies $\left(q_{t k}\right)$, a linear trend specific per product (captured with the coefficients $\eta_{s}$ ), and the product presentation fixed effects $\gamma_{i}$. Thus, in Equation 1, our coefficient of interest $\beta_{j}$ represents the jump on the price/quantities after the regulation started, conditional on a linear trend, seasonal effects, and net of time-invariant characteristics of each product presentation. 


$$
Y_{i t}=\alpha+\sum_{j=1}^{3} \beta_{j} \cdot P C_{j i} \times A_{t}+\sum_{k=1}^{3} \gamma_{k} q_{t k}+\sum_{j=1}^{3} \eta_{j} \cdot t \times P C_{j i}+\gamma_{i}+u_{i t}
$$

Equation 2 adds a partition to the price categories based on the regulatory status. Here, $R_{h i}$ allows us to differentiate products without any type of regulation $(h=1)$ from those with a "regulated-ingredient" according to our previous definition $(h=2)$, and from those directly regulated $(h=3){ }^{13}$ This extra partition will allow us to understand whether the regulation had a pure "mechanical" effect, decreasing the price of directly affected products, or whether it induced a competitive response on other oral contraceptives that are sufficiently similar, based on a shared regulated active component.

$$
Y_{i t}=\alpha+\sum_{j=1}^{3} \sum_{h=1}^{3} \beta_{j h} \cdot P C_{j i} \times R_{h i} \times A_{t}+\sum_{k=1}^{3} \gamma_{k} q_{t k}+\sum_{j=1}^{3} \eta_{j} \cdot t \times P C_{j i}+\gamma_{i}+u_{i t}
$$

This analysis will provide an idea of the wholesale market trends and the degree of competition between products, revealed by the price response of non-directly regulated products. Nonetheless, the wholesale level analysis does not involve any characteristic of the final user of the product. In the next section we explain how we capture prices at the community pharmacy level.

\subsection{Pharmacy level data: simulated client methodology}

We employ the SCM (Kwan et al. 2019) to understand whether the products in the different price categories were targeted to a specific audience according to SES level and whether this targeting strategy was modified as a result of the regulation. Our data collection comprised Bogotá, a metropolis of more than eight million inhabitants with a wide SES distribution.

The data collection was carried out in two periods of time: right before the regulation took place, and a couple of quarters after. Figure 1 illustrates this timing. The shaded bars represent data collection points before (labeled as SCM1) and after the regulation (labeled as SCM2). Panel (a) confirms that price adjustments were effective at the due date of the regulation, allowing us to check whether this price adjustment was transmitted to community pharmacies. Panel (b) evidences the increasing of sold units of intermediate and bottom regulated contraceptives.

\subsubsection{Selection of contraceptives for the audit study}

We devise a standardized script for collecting the prices and availability from six contraceptive brands, with two different active ingredients or progestins. Table 2 lists the six brands included in the study. Each column represents a progestin. Within each column, we selected three brands with different targets: a high-end, a mid-range, and a low-end brand, respectively. The high-end products and one of the mid-range product (Bellaface) were classified in the Top price category,

\footnotetext{
${ }^{13}$ We take regulated products following the Circular 07/2018. Two additional products, Qlaira and Evely, were regulated by Circular 09/2019 in May 2019. Therefore, in our exercise they are considered as non-regulated CUMs.
} 
Figure 1: Wholesale level quarterly average prices according to price category and regulation status

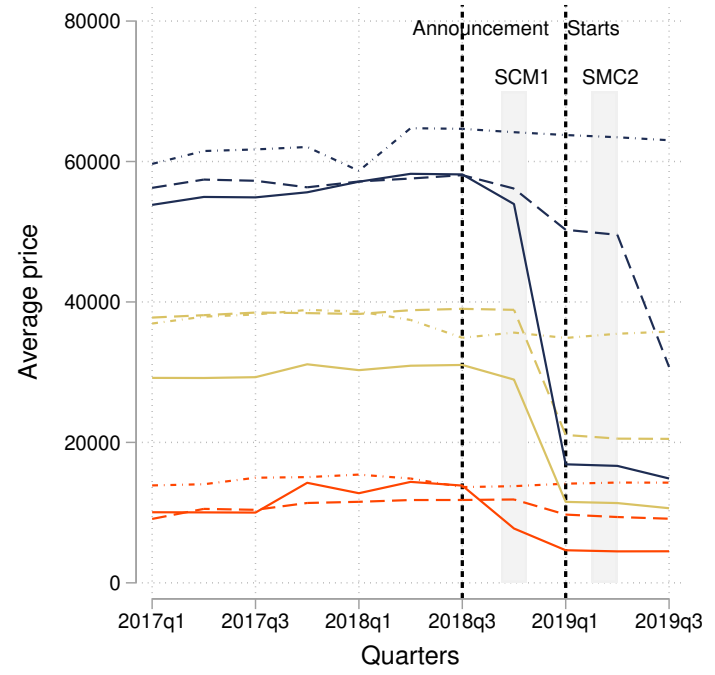

(a) Average price

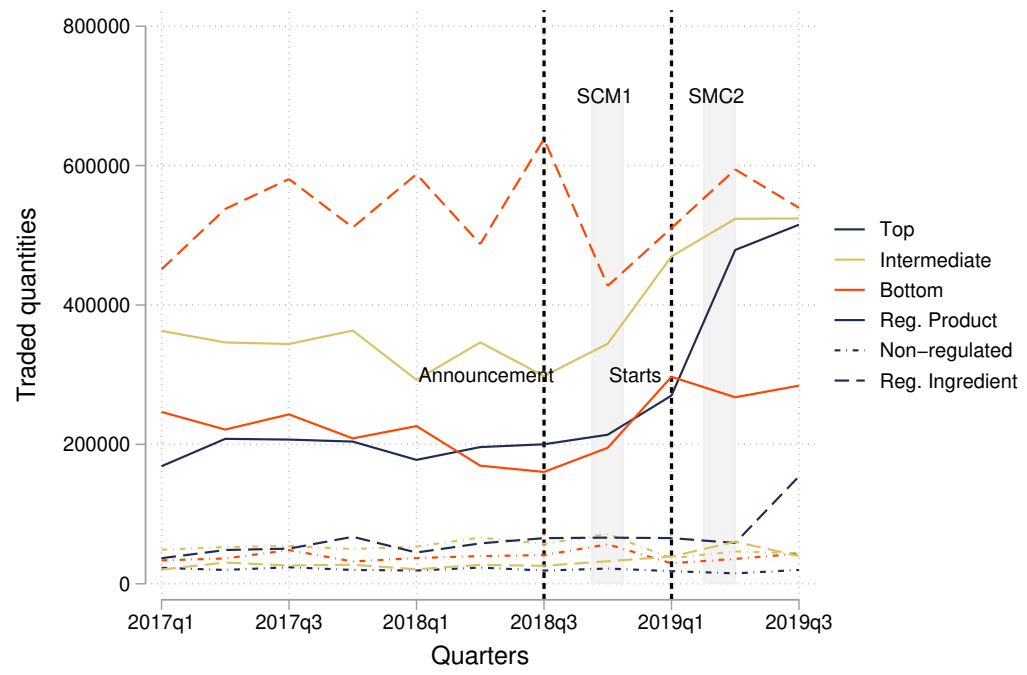

(b) Average sold units

Note: Calculations based on administrative data records from SISMED including all oral contraceptives with registered transactions at least every year. The first vertical dashed line corresponds to the regulation announcement, at 2018Q3 (6 August). The second vertical dashed line corresponds to the quarter when the regulation started (2019Q1). Shaded bars correspond to the periods in which the audit study was conducted

while the other three audited brands were classified in the Medium price category. Equally important, the two brands sharing a row were from the same pharmaceutical distributor. We did not select any brand in the Bottom price category because it does not include any fourth-generation contraceptive, which are the products from which an expansion is desired and assessed in this study.

Figure 2 displays, for each product presentation, the mapping of prices before (horizontal axis) and after the regulation (vertical axis). The marker shape for each product corresponds to the definition of the variable $R_{h i}$ in Equation 2. Blue squares correspond to directly regulated products; green triangles to regulated ingredients, and red circles correspond to cases where none of the products with the same active ingredient were regulated 14 Note that the red circles are scattered just above the $45^{\circ}$ line (i.e., almost no price difference over time), whereas most of the triangles, and all squares, fall below this line.

The six audited brands appear labeled in Figure 2. Low-end brands are in the bottom-left side

\footnotetext{
${ }^{14}$ Bellaface and Qlaira have different ATC codes. However, both contraceptives have the same progestin (Dienogest) as the principal active ingredient, but compounded with different estrogens. That is the reason why we classify those contraceptives in the same category. Dienogest is one of the progestins classified in the fourth-generation oral contraceptives. While we consider products within the same progestin market as competitors, in the Appendix we present exercises where we use the exact ATC code (progestin-estrogen).
} 
Table 2: Selected contraceptive brands for the audit study. Brand name in italics. Pharmaceutical manufacturer in parenthesis.

\begin{tabular}{cccc}
\hline \multirow{2}{*}{ Target } & Dienogest & Progestin & \multirow{2}{*}{ Regulated? } \\
\hline High-end & Qlaira (Bayer) & Drosperinona & \\
Mid-range & Bellaface (Abbott-Lafrancol) & Yaxibelle (Abbott-Lafrancol) & No-Yes $^{a}$ \\
Low-end & Dienille (Exeltis) & Yrospera (Exeltis) & No-No \\
\hline
\end{tabular}

${ }^{a}$ By the time of the announcement of the price cap regulation, Qlaira was not listed among the regulated brands despite its price: the active substance dienogest and estrogen, whose pharmaceutical form is in tablet or capsule, belongs to the relevant market 602, however, Qlaira (Bayer) and Evely (Lafrancol) have an estrogen that has a different pharmacokinetic profile than the others, which made it necessary to create the relevant market $602 \mathrm{~b}$. Qlaira was regulated 9 months later after correcting this mistake. On the other hand, Yasminiq was included in the regulation, but the pharmaceutical distributor reduce its price some weeks before the regulation took place.

of the figure, mid-range brands at the center of the figure, with respect to the horizontal axis (price before the regulation); and the two high-end brands are at the right side of the figure with respect to the horizontal axis, but far from each other (recall that Qlaira was not regulated at the time).

\subsubsection{Data collection before the regulation}

\section{Sampling strategy of community pharmacies}

Our sampling strategy was based on the distance of pharmacies to the stations of the mass transportation system in the city, Transmilenio. We aimed for community pharmacies that were located in areas with a considerable influx of visitors, securing a sufficient inventory rotation that allows owners to rapidly incorporate the price cap regulation with the new stocks. The initial inventory of pharmacies was completed using Google Maps. Some of the registered stores were moved, or were permanently closed. 15

The initial sample included 298 community pharmacies, and we were able to audit 213 (71.5\%). We randomly assigned two features that varied in each audit. First, the active component of the three brands for which we asked the price. That is, each column in Table 2 is a treatment: the Dienogest and the Drosperinona treatments. Since we visited each pharmacy once, we either have information regarding the availability and prices of Qlaira, Bellaface, and Dienille in the Dienogest treatment; or this same information for Yasminiq, Yaxibelle, and Drospera in the Drosperinona treatment. The second dimension that we randomly varied was the gender of the simulated client.

We conducted the audits in December 2018, right before the price cap regulation took place. Research assistants acting as potential buyers worked in pairs, typically one woman and one man, and were assigned to one of the mass transport system zones, which are geographically distributed across the city. During the fieldwork, after one of the pre-assigned pharmacies was located, the simulated client entered and employed the script to collect the information. If there

\footnotetext{
${ }^{15}$ For security reasons, we skipped the visits to the pharmacies in the vicinity of a transport stations located in a red-light district with considerable theft issues.
} 
Figure 2: Prices before and after the regulation registered in SISMED

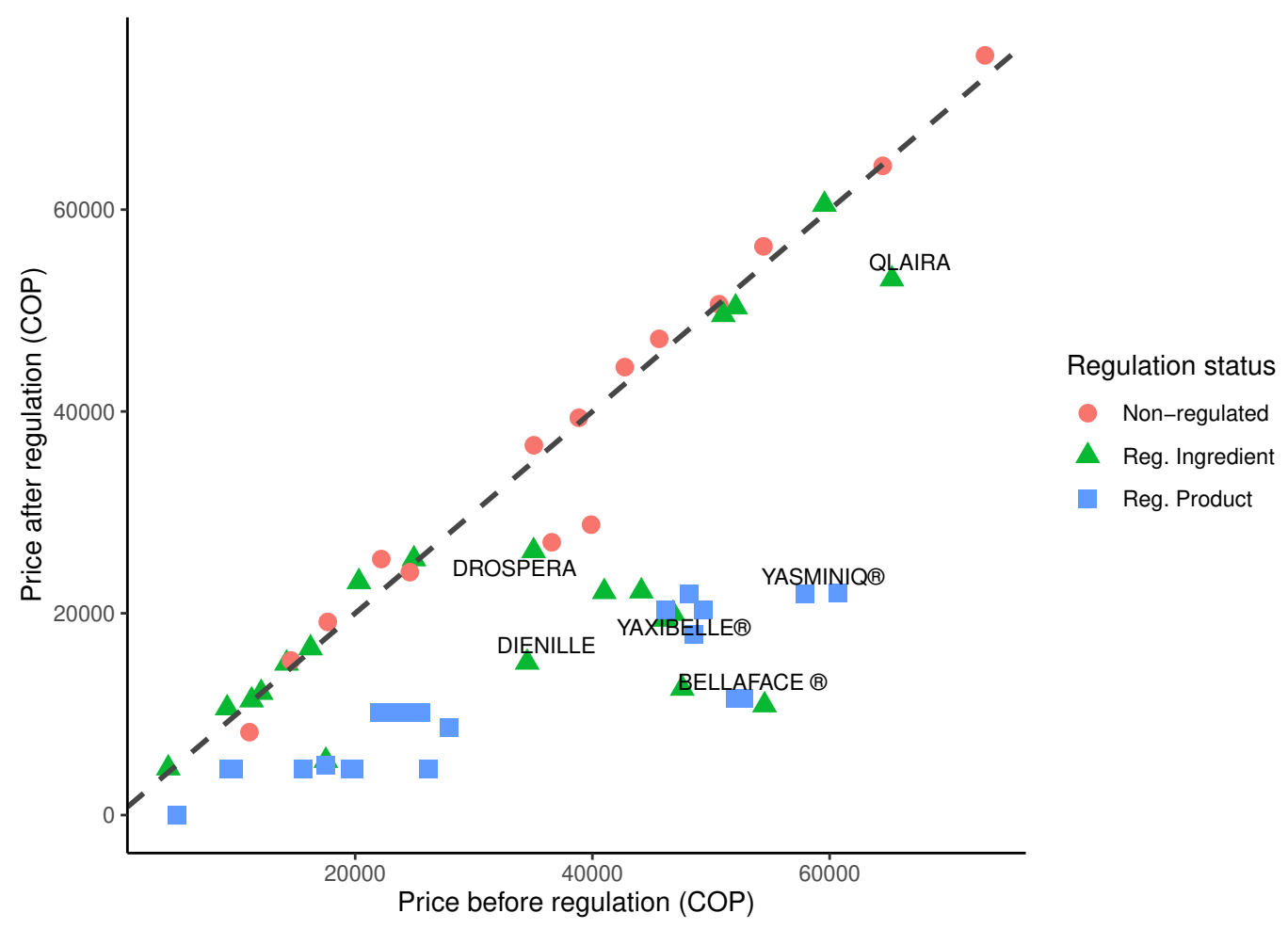

Note: Blue squares correspond to the regulated products, green triangles to regulated ingredients, and red circles to the non-regulated products. Products are defined by their unique combination of the drug name, dosage, and presentation (CUM code). We aggregated medications by the progestin they use as an active ingredient. The six brands chosen in the audit experiment are tagged. Calculations are based on administrative data records from SISMED. We included 56 oral contraceptives brands that reported prices at least in one period both before and after regulation. Drospera and Dienille were only published in one period in our period of analysis, and therefore, we imputed their prices from the public SISMED database. We conducted a similar exercise with the active ingredient progestin-estrogen in Figure A2 (see Appendix).

were customers waiting in the pharmacy, the simulated client left and visited the pharmacy 5-10 minutes later.

\section{Script employed in the audits}

The script for our simulated client presents three advantages. First, it allows us to interact with pharmacy vendors in a systematic and blinded fashion. This feature is particularly important in the context of the new regulation. Sellers might avoid audits from pharmaceutical companies and government offices, and therefore they might be reluctant to provide long lists of prices, or simply misreport prices. Second, it allows us to collect information on prices and the availability of three contraceptive brands per audited pharmacy. Third, it grants that, regardless of the gender of the 
simulated client, the seller could infer that the contraceptive pills were not for herself or himself ${ }^{16}$

The script says:

Good morning/afternoon, the Physician prescribed to my younger sister these pills called [name of the high-end brand]. I was told that these other two brands have the same effect, and they are cheaper.

[The buyer shows a handwritten piece of paper with the three names of the brands sharing the same active component.]

Do you have them? How much they cost?

[The buyer writes down the prices either (i) in the piece of paper, or (ii) in her/his cellphone.]

The three brands were sorted from the most to the least expensive, before the price regulation. The main reason is that it becomes more credible to further ask about the cheaper brands. Besides, the high-end brands, Qlaira and Yasminiq, are typically prescribed in case of acne. We originally conceived this feature as a quality control measure in the interaction with the vendor by coding whether the vendor asked if the pills were prescribed for acne. However, only in $2.7 \%$ of the cases the vendor posed questions related to acne problems. We excluded this outcome variable from further analyses.

\subsubsection{Data collection after the regulation}

Three months after the initial data gathering we conducted the follow-up collection. The purpose was to study what occurred with the availability and the prices of the six contraceptive brands originally audited. Due to resource constraints, during this second stage, we combined two collection methods: in-presence visits to sixty percent of the originally audited pharmacies, and telephone calls to the remaining forty percent of the pharmacies.

\section{Data collection from in-presence visits}

We repeated the use of the protocol described in Section 2.2.2 in the sixty percent of pharmacies assigned to in-presence visits. Research assistants acting as simulated clients were reassigned to different areas of the city, to make sure that the client was not recognized by the vendor from a past interaction.

The use of the same protocol, including the script, is advantageous because both waves of data collection are as similar as possible. On the other hand, using the same script has the disadvantage of increasing the chances of being detected by the pharmacy's vendor. We argue that there are two reasons why the chances of detection remain low. First, the three months that passed between the pre-regulation and the post-regulation audits. Second, in $48 \%$ of the pharmacies there were

\footnotetext{
${ }^{16}$ This is important to prevent a "second-order moral hazard" problem (Balafoutas et al. 2015), defined as the tendency of the seller to anticipate moral hazard from the buyer by acquiring a good that is not for herself. In our SCM the concern is not that simulated clients would be charged a different price based on their gender, but the fact that less attention might be paid to male with respect to female clients.
} 
two or more vendors at the time of the initial visit, reducing the likelihood that the same vendor interacted twice with our auditors.

\section{Data collection using telephone calls}

During the first data collection process we gathered the telephone numbers of the community pharmacies in our sample since they might differ from those reported on the internet. The numbers were not available for all the pharmacies. The main reason is that, for some pharmacy chains, home delivery is a separate, centralized business. Multiple audited pharmacies that were affiliated with one of the distributor chains provided always the same telephone number.

Since the logistic cost of phone audits was lower, we did not employ the script described in Section 2.2.2. Instead, we called three times to each one of the community pharmacies with a unique telephone number, once per each contraceptive brand audited in the initial data collection process. We asked for the availability and price of a given brand. Calls to a given drug store were made on different days, minimizing the chance that phone respondents suspected about the audit. We called up to three times in case a call was not replied. After the third failed attempt we labeled the drug store as not reachable by phone. This occurred with $35.6 \%$ of the community pharmacies for which we have a telephone number. All the phone calls were made by two research assistants, one woman and one man, who did not take part in the in-presence audits in neither of the stages.

\section{Results}

We start by displaying the regression results at the wholesale level in terms of prices and quantities, followed by the results regarding the drop in prices and availability of the six contraceptive brands studied in our audit analysis.

\subsection{Wholesale level}

Table 3 shows changes over prices and quantities sold, based on administrative records. Columns 1 and 2 refer to the average price per product, and columns 3 to 4 refer to the logarithm of quantities as the dependent variable.

Column 1 reveals sizeable reductions with respect to the benchmark price. Relative to the pre-intervention average, we observe reductions of 0.49 for products in the Top category. This is equivalent to a $35.7 \%$ reduction of the mean price category reported in Table 1 . The price reductions for the Intermediate and Bottom categories were $0.36(46.6 \%)$ and $0.08(33 \%)$, respectively.

The differences become particularly after separating products by regulation type ${ }^{17}$ Column 2 reveals that prices did not change for contraceptives whose active ingredients were not regulated. To the benchmark price, the average reduction for regulated products in the Top category was of 1 $(92 \%)$. For regulated-ingredients, the point estimate of the reduction was of $0.35(27.4 \%)$, but the

\footnotetext{
${ }^{17}$ In Table 3 we consider all oral contraceptives with the same progestin as part of the same active ingredient group. Table A3 in the Appendix, employs a narrower definition by considering both progestin-estrogen combinations. The results are similar to those presented in this section.
} 
Table 3: Regulation effects by price category at wholesale level

\begin{tabular}{|c|c|c|c|c|}
\hline & & (2) & (3) & \multirow{2}{*}{ tity) } \\
\hline & \multicolumn{2}{|c|}{ Relative price } & Ln(Quantity) & \\
\hline Top $\times$ After & $\begin{array}{c}-0.490^{* * *} \\
(0.140)\end{array}$ & & $\begin{array}{l}-0.0115 \\
(0.244)\end{array}$ & \\
\hline Interm. $\times$ After & $\begin{array}{c}-0.364^{* * *} \\
(0.0502)\end{array}$ & & $\begin{array}{c}0.186 \\
(0.124)\end{array}$ & \\
\hline Bottom $\times$ After & $\begin{array}{c}-0.0858^{* *} \\
(0.0345)\end{array}$ & & $\begin{array}{l}-0.0797 \\
(0.215)\end{array}$ & \\
\hline Top $\times$ Non-regulated $\times$ After & & $\begin{array}{l}-0.0540^{*} \\
(0.0294)\end{array}$ & & $\begin{array}{c}-0.466^{* *} \\
(0.196)\end{array}$ \\
\hline Top $\times$ Reg. Ingredient $\times$ After & & $\begin{array}{l}-0.349^{*} \\
(0.197)\end{array}$ & & $\begin{array}{r}-0.0807 \\
(0.382)\end{array}$ \\
\hline Top $\times$ Reg. Product $\times$ After & & $\begin{array}{r}-1.003^{* * *} \\
(0.0464)\end{array}$ & & $\begin{array}{l}0.424^{*} \\
(0.231)\end{array}$ \\
\hline Interm. $\times$ Non-regulated $\times$ After & & $\begin{array}{l}-0.0599 \\
(0.0477)\end{array}$ & & $\begin{array}{l}-0.286^{*} \\
(0.162)\end{array}$ \\
\hline Interm. $\times$ Reg. Ingredient $\times$ After & & $\begin{array}{c}-0.442^{* * *} \\
(0.122)\end{array}$ & & $\begin{array}{l}0.626^{* *} \\
(0.277)\end{array}$ \\
\hline Interm. $\times$ Reg. Product $\times$ After & & $\begin{array}{r}-0.467^{* * *} \\
(0.0363)\end{array}$ & & $\begin{array}{c}0.191 \\
(0.151)\end{array}$ \\
\hline Bottom $\times$ Non-regulated $\times$ After & & $\begin{array}{l}-0.0330 \\
(0.0276)\end{array}$ & & $\begin{array}{l}-0.300^{*} \\
(0.164)\end{array}$ \\
\hline Bottom $\times$ Reg. Ingredient $\times$ After & & $\begin{array}{l}-0.0759 \\
(0.0573)\end{array}$ & & $\begin{array}{r}-0.0235 \\
(0.150)\end{array}$ \\
\hline Bottom $\times$ Reg. Product $\times$ After & & $\begin{array}{r}-0.173^{* * *} \\
(0.0157)\end{array}$ & & $\begin{array}{l}0.0718 \\
(0.480)\end{array}$ \\
\hline Constant & $\begin{array}{l}0.777^{* * *} \\
(0.0367)\end{array}$ & $\begin{array}{l}0.775^{* * *} \\
(0.0350)\end{array}$ & $\begin{array}{c}9.059^{* * *} \\
(0.133)\end{array}$ & $\begin{array}{c}9.054^{* * *} \\
(0.132)\end{array}$ \\
\hline Observations & 551 & 551 & 551 & 551 \\
\hline Number of drugs & 52 & 52 & 52 & 52 \\
\hline R-squared & 0.496 & 0.720 & 0.0288 & 0.126 \\
\hline Adjusted R-squared & 0.488 & 0.712 & 0.0126 & 0.101 \\
\hline
\end{tabular}

Notes: Regressions based on 52 drugs for which there are registered one transactions at least every year in the period of analysis from 2017Q1 to 2019Q3. All regressions include a price-level specific linear trend, quarter seasonal dummies, and drug fixed effects. Products are defined by their unique combination of drug name, dosage, and presentation (CUM code). We aggregated medications by the progestin used as an active ingredient. Clustered standard errors by drug-level are shown in parentheses. Significance levels: ${ }^{*} \mathrm{p}<0.1 ;{ }^{* *} \mathrm{p}<0.05 ;{ }^{* * *} \mathrm{p}<0.01$. 
estimate is less precise. For products in the Intermediate category, the price reduction for directly regulated products was equivalent to $0.46(78 \%)$. For regulated-ingredients this reduction reached $0.44(55 \%)$. For products in the Bottom category, the price reduction of regulated products was 0.17 $(73 \%)$ with respect to the pre-regulation mean price.

As for quantities, Column 3 reveals an increase in the Intermediate price category, although they are imprecisely estimated, and its coefficient is not statistically different from zero. However, Column 4 reveals that once the products are separated by regulation type, the traded quantities of regulated products in the Top price category increased by $52.8 \%$. For regulated-ingredient products in the Intermediate category the increase reached $87 \%$. These large increases are evident in Figure 1. By contrast, for non-regulated products there is evidence of a reduction in the traded quantities, which fell by 59\%, 33\% and 35\% in the Top, Intermediate, and Bottom price categories, respectively. The same patterns are observed when considering the non-restricted sample with 79 products (see Table A4 in the Appendix).

\subsection{Prices at the community pharmacy level}

We show in Section 3.1 that the regulation capped the prices at the wholesale market level. In this section, we validate whether this price reduction also reduced the prices at the community pharmacies level, three months after the regulation took place. Figure 3 depicts the observed prices before (in black) and after the regulation (in gray). The dashed horizontal line represents the average price of contraceptives in the Intermediate price category before the regulation. Note that the average price dropped for all brands, except for Qlaira, which at the time of our second data collection was yet not regulated.

Although Yasminiq is a High-End brand, its average price before the regulation falls below the average prices of the mid-range brands, Yaxibelle and Bellaface. This pattern is the result of the decision of its pharmaceutical distributor to decrease the prices of Yasminiq at the pharmacies, before the regulation started to operate (and it is also the reason why this product is displayed in dark gray in Figure 3). To give an additional idea of the variation in the prices for Yasminiq before the regulation, the standard deviation of its prices is 18,145 COP, while for the other audited brands this deviation dwells between 2,715 COP and 9,074 COP.

Recall that Qlaira and Yasminiq have the same pharmaceutical distributor. Hence, the pattern of observed prices suggests a complex pricing strategy in the context of post-regulation for this company. Qlaira was not regulated and its price was not reduced, even if brands with the same active component set an average price that considerably fell below the price cap. On the other hand, the price of Yasminiq was reduced to levels comparable with other brands with the same active component, even some weeks before the regulation started to apply. Although our data does not allow us to tell more about this pricing strategy, it was the combination of wholesale and pharmacy-level data that made this pattern evident.

Table 4 confirms the price reduction associated with the regulation that we show in Figure 3 , Columns 1 and 2 reveal that the effects are evident for all the contraceptive categories, except for Qlaira, the non-regulated High-end brand. The statistical comparisons of coefficients, reported at the bottom of the table, confirm that the largest price drops occur for the mid-range contracep- 
Figure 3: Average prices of the six audited brands.

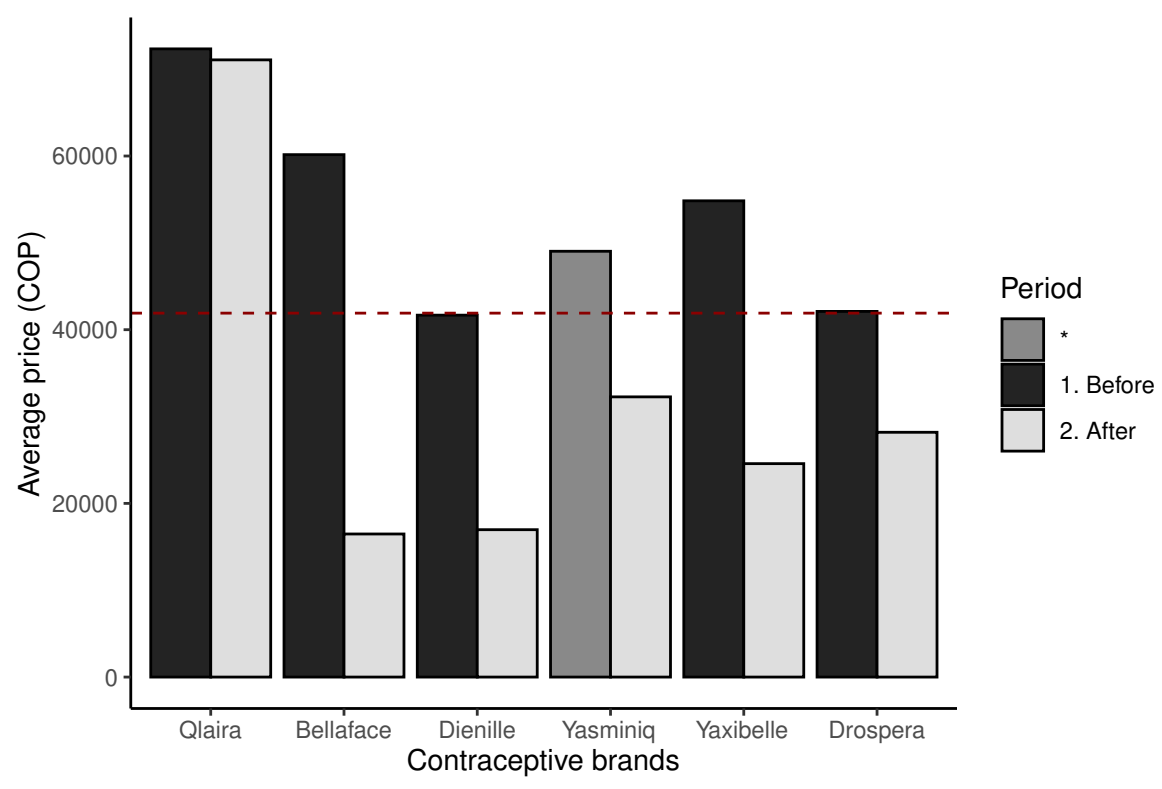

Note: Average price for Yasminiq before the regulation is displayed with a different color because the pharmaceutical distributor reduced the prices before the regulation started to operate. For Yasminiq, we use information before December $18^{\text {th }}$ as the "before regulation" period.

tives, whose difference with respect to high-end and low-end products is statistically significant ${ }^{18}$ Columns 3 and 4 report an analysis aimed at validating price differences by SES levels. We observe that the price reduction did not differ between pharmacies located in High and Low SES areas (see the test for coefficients at the bottom of the table).

\subsection{Availability at the community pharmacy level}

We learned that the price reduction associated with the regulation at the wholesale level was rapidly transmitted at the pharmacy level. In this section we explore whether this price reduction was accompanied by a change in availability. Ex-ante, it is not clear whether availability increases, as one would expect given the higher transacted quantities observed at the wholesale level; or, by contrast, availability decreases due to stocking patterns from distributors or consumers.

Figure 4 displays the availability of the six audited brands before (in black) and after (in light

\footnotetext{
${ }^{18}$ An attentive reader might wonder how the early price reduction of Yasminiq would affect the estimated coefficients. We performed a robustness exercise in which we reassigned for Yasminiq the value of the variable After, indicating the starting day of the regulation. We artificially shifted backward the starting day of the regulation for Yasminiq up to twelve days, altering the proportion of observations for which this brand was observed before and after the regulation. The results of this robustness exercise are displayed in Figure A3 in the Appendix. In eleven out of twelve regressions, the point estimate from our original computation falls within the confidence interval of the re-estimated coefficient of interest (Yasminiq $\times$ After Regulation).
} 
Table 4: Price effects in ranges and SES Level after regulation based on pharmacy-level data

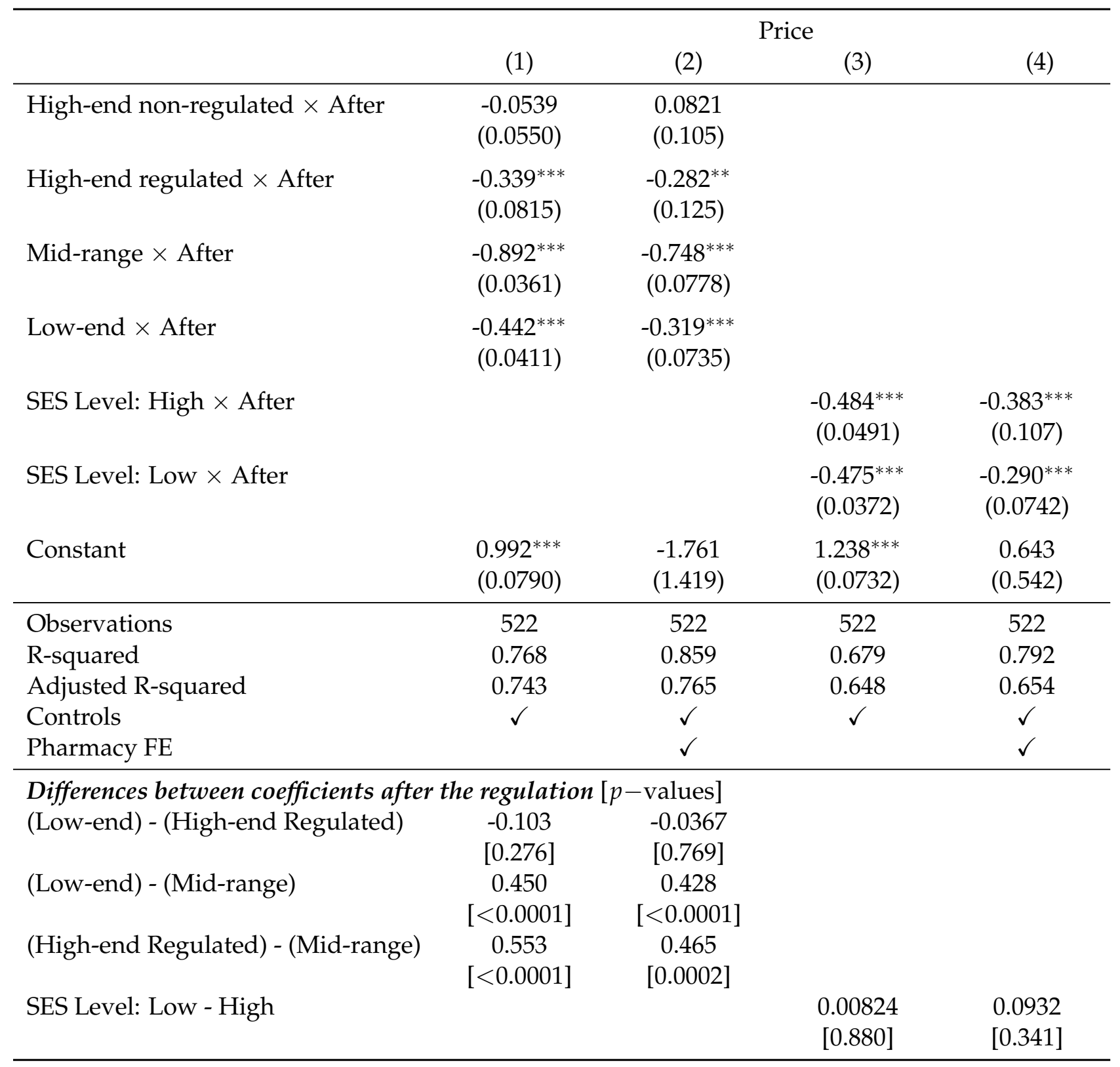

Notes: ${ }^{*} \mathrm{p}<0.1 ;{ }^{* *} \mathrm{p}<0.05 ;{ }^{* * *} \mathrm{p}<0.01$. Clustered standard errors by drugstore are shown in parenthesis. The dependent variable in all specifications is the relative price quoted by the pharmacy's regent. Controls included: Socioeconomic status wherein drugstores were located, contraceptives availability, drugstores zone, experimenter identification, seller gender, seller age, chain and store size. 
Figure 4: Availability of the six audited brands.

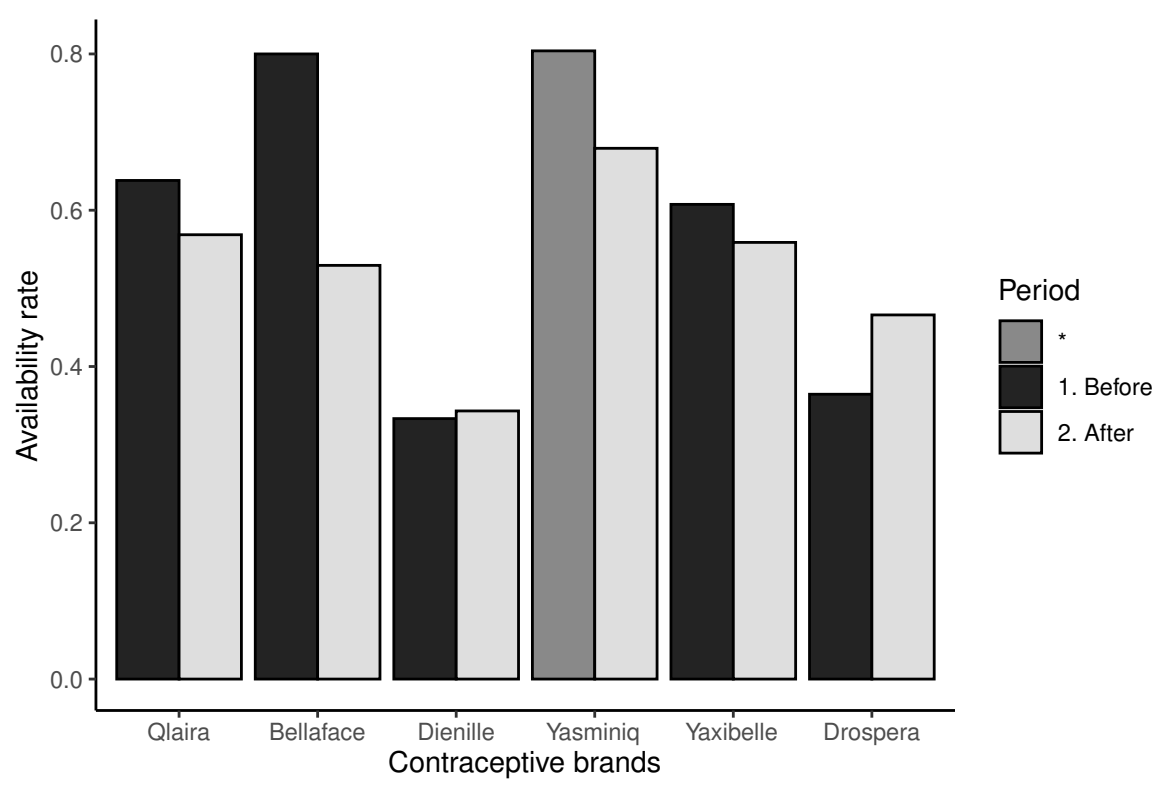

Note: Availability for Yasminiq before the regulation is displayed with a different color because the pharmaceutical distributor reduced the prices before the regulation started to operate. For Yasminiq, we use information before December $18^{\text {th }}$ as "before regulation" period.

gray) the regulation $\sqrt{19}$ For the high-end (Qlaira and Yasminiq) and mid-range brands (Bellaface and Yaxibella), product availability decreases after the introduction of the regulation. We conjecture that this decrease in availability obeys to a destocking pattern, triggered by the belief that the price cap regulation was temporary 20 By contrast, for the low-end brands we either observe an increase in availability (Drospera), or no difference at all (Dienille).

An important concern is whether there is a SES gradient on availability. One motivation for controlling prices is to ensure that the product is accessible for the entire population, but this objective is undermined if the product cannot be found in poorer areas. Figure 5 depicts the spatial availability of mid-range brands in the city before and after the regulation. We find that the number of pharmacies in which mid-range brands became unavailable (yellow triangles) tripled the pharmacies in which the regulation had the opposing effect, and mid-range brands became available (blue squares). This map shows that mid-range brands are widely available from the extended Central area of the city to the Northeast of the city, which mostly corresponds to highincome areas. In most of those pharmacies, the products remained available after the regulation

\footnotetext{
${ }^{19}$ The availability of Yasminiq before the regulation is displayed with a different color (dark gray) because its pharmaceutical distributor started to reduce its price before the regulation started to operate. We observed that in some audits conducted in mid-December the prices were already under the cap.

${ }^{20}$ The sharp decrease in the availability of Bellaface was reported by the Colombian newspapers. See: https://www . elespectador.com/noticias/salud/por-que-escasea-el-anticonceptivo-bellaface-en-colombia/
} 
was introduced (green diamonds). In other areas of the city, mostly middle-class residential areas, access before the regulation was relatively low, and in most of them the audited brands remained unavailable (red circles). The pattern for high-end brands is very similar to the one presented here (the analogous figures for the high-end and low-end brands are displayed in the Appendix, see Figures A4 and A5).

Table 5 confirms this pattern using a statistical analysis for availability as an outcome variable. We report in this table the average marginal effects from a logistic regression. Columns 1 and 2, differing only on the inclusion of pharmacy fixed effects, show that mid-range products became less available than products in other price ranges. Column 3 replicates the specification from Column 1 with the subsample of Column 2, showing that this result is not an artifact of the selection of pharmacies included in the model with fixed effects.

We employed the regressions reported in Columns 4 to 6 to explore variations in availability based on spatial differences in SES. The test reported at the bottom of Table 5, comparing High versus Low SES after the regulation, provides suggestive evidence that the reduction in availability was larger in Low SES areas. This reduction is statistically significant in two of our models.

\section{Discussion}

Our analysis at the wholesale level yields two main results. First, following the price cut, there was a massive expansion of transacted products, especially in the regulated products of the Top price category and the products with a regulated-ingredient in the Intermediate category. The observed increase in demand suggests that distributors decided to raise their stock to anticipate higher prices in the future. Unfortunately, the available data is limited to a single year after the regulation. Therefore, we cannot determine which proportion of the increase responds to this stocking pattern and to the actual consumer demand expansion.

Second, the price of products with a regulated-ingredient dropped, whereas the price for nonregulated products with a different active ingredient was not affected. This result suggests that distributors consider active principles as non-substitutable, and active ingredients constitute the appropriate, relevant market even though all oral contraceptives are therapeutic substitutes.

The price reduction can be interpreted as a response to consumers, who might substitute out non-regulated products without a strong brand, or without a substantially competitive price, in favor of market leaders. Since the price reduction is not negligible, one would expect that several of the rest of the products will be out of the market in the following years.

These findings emerge from the analysis of average tendencies of prices and quantities. Nonetheless, we can also study the case of some particular brands that were not regulated despite being at the top of the distribution. In contrast, their cheaper competitors sharing the same active ingredient category had to reduce their prices substantially. This is the case of Qlaira and Gianda, which are depicted as the two rightmost green triangles in Figure 2. Interestingly, the price response of those market leaders was null or very small. Thus, as in Frank and Salkever (1992), the leader of the market (defined by the active ingredient) is not affected by the drastic price reduction of the competitors, even in this context where all products are branded. This evidence speaks in favor of market leaders holding considerable market power to avoid adjusting prices despite the average 
Figure 5: Availability of mid-range contraceptives in the city according to socioeconomic level

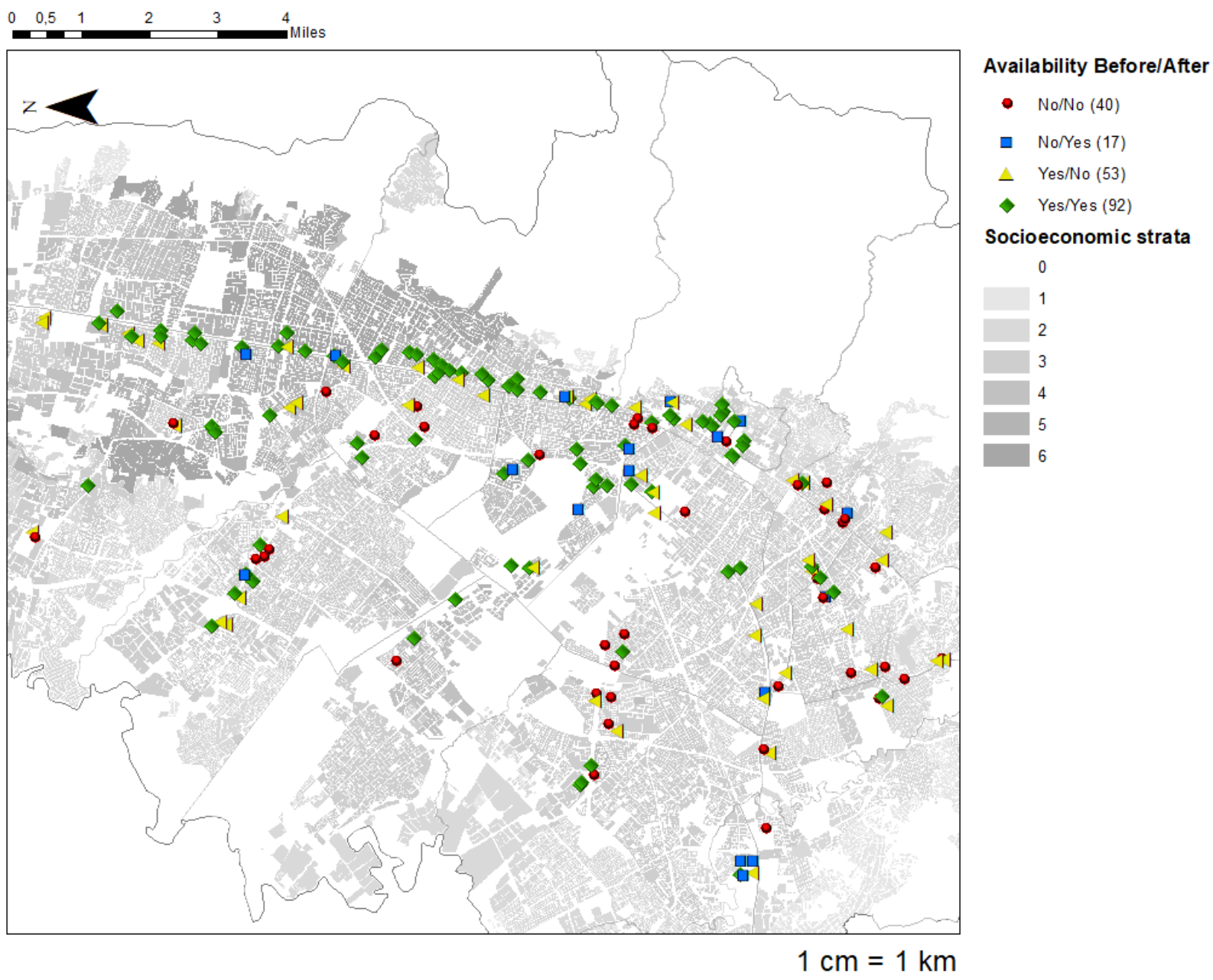

Note: Own calculations based on our two rounds of data collection. The linear pattern on the location of pharmacies obeys to our sampling strategy based on the proximity to stations of the transportation system. 
Table 5: Impact on availability (average marginal effects)

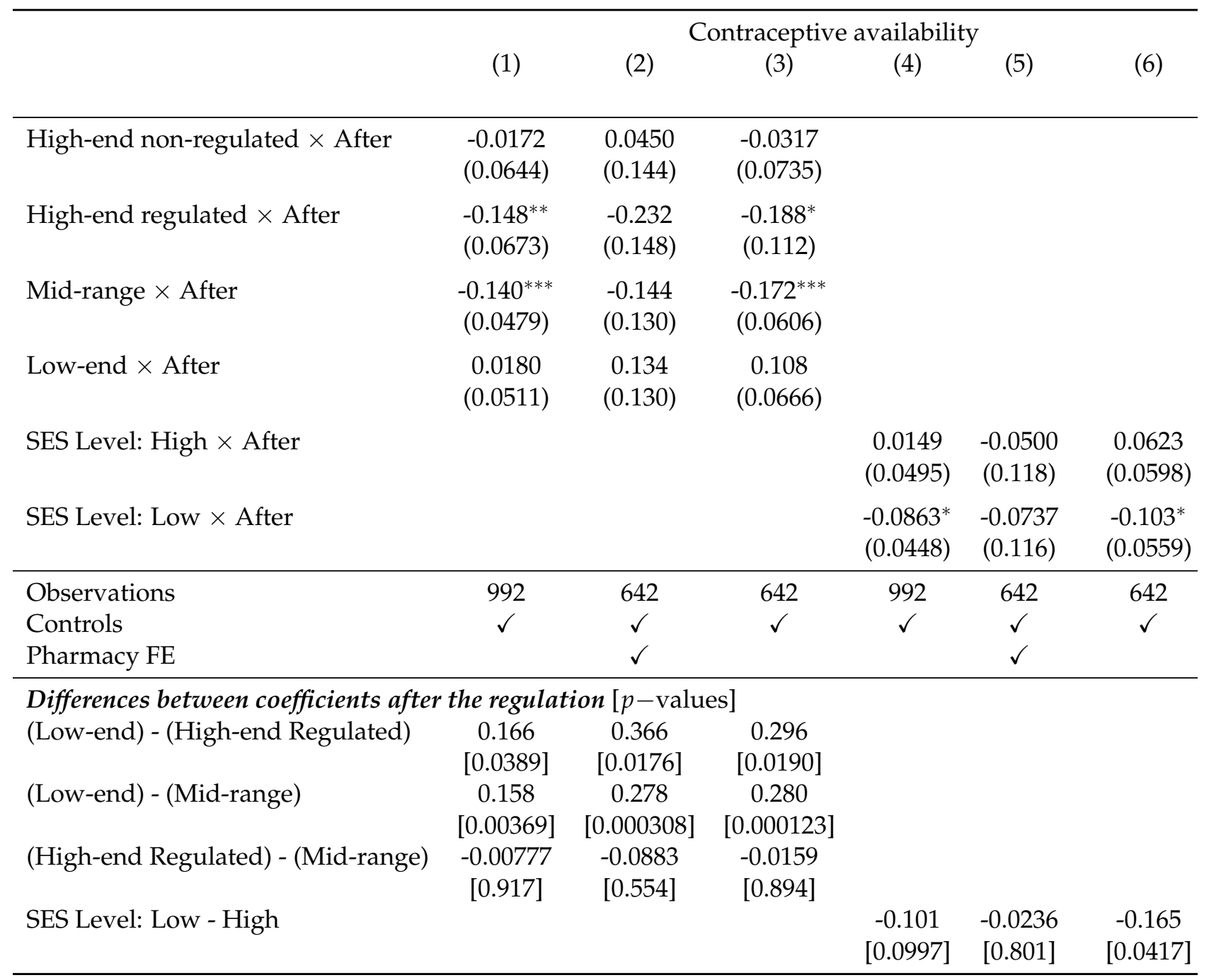

Notes: ${ }^{*} \mathrm{p}<0.1 ;{ }^{* *} \mathrm{p}<0.05 ;{ }^{* *} \mathrm{p}<0.01$ Controls included: Socioeconomic status wherein drugstores were located, contraceptives availability, drugstores zone, experimenter identification, seller gender, seller age, chain and store size. 
large effect we report in our wholesale level analysis.

The wholesale analysis is based on massive transactions of large distributors, which have to plan the demand for the next months-even above a year- of pharmaceutical products. Hence, the effects at this level do not necessarily reflect the final demand of individual consumers. Here is where our analysis at the community pharmacy level sheds some light on whether the price-cap regulation led to an expansion of mid-range and high-end products from the high-SES areas into the low-SES areas.

There are two main results to highlight from our audit study. First, even if the administrative data reveals an increase in sales of the leading contraceptive products, our pharmacy level data shows that there was no increase in the availability of such products in Bogotá. If anything, it became harder to find these contraceptive brands in the low-SES neighborhoods of the city. This result is also in line with the stocking argument described above, instead of favoring the alternative hypothesis of a sudden increase in demand from consumers who switched from other contraceptive methods or older generations of oral contraceptives.

Second, price reductions were passed from the wholesale level to the community pharmacy level for regulated and non-regulated products. Nonetheless, for Qlaira, the non-regulated Highend contraceptive, we did not observe a change of price at the pharmacy level. As we discussed above, this particular brand and its pharmaceutical distributor hold sufficient market power to engage in more complex pricing strategies. We expect that these strategies can be better understood when sufficient data, reflecting medium-term effects, becomes available.

Summing up, the complexity of the contraceptives market in Colombia can be analyzed in two dimensions: purchasing power and loyalty. Our results shed some light on the co-existence of different pricing patterns after the regulation. Some consumers with high purchasing power might remain as loyal customers, as the case of the non-regulated Qlaira suggests. On the other hand, non-loyal customers with purchasing power are willing to obtain cheaper alternatives with the new regulation's entry, putting pressure on distributors to reduce their prices or abandon the market. Looking now at consumers with low purchasing power, it seems that insufficient availability prevents them from switching to high-end regulated products, even if their price considerably decreased. Instead, they appear to switch to the low-end regulated products. At the aggregate level, this pattern goes in line with the lack of expansion of the high-end and mid-range products into the low-SES market.

Unfortunately, our data do not allow us to explore two crucial issues. First, a potential downside of direct price regulation is the reduction of products in the market and the slower entrance of new alternatives. These are processes that take years to be observed. Second, we cannot observe whether there is an expansion in the usage of oral-contraceptives, and neither in which proportion is determined by accessibility or substitutability. In other words, we cannot disentangle those previously constrained due to the price of those who switch from an alternative contraceptive product.

In the medium- and long-term, there might be some consequences of this regulation that we cannot consider yet, given the available data. However, these consequences would be essential to determine the net welfare gain of this policy. First, since some products are likely to disappear from the market with this regulation, this market's competitive structure might be affected. For 
instance, certain laboratories cannot be sustained in the pharmaceutical market as a whole (Zhang et al., 2016). Second, laboratories' intertemporal decisions of releasing next-generation contraceptives in the country might be distorted, as part of a strategic decision in the global market (Costa-Font et al., 2014, Brekke et al., 2016). Third, pharmaceutical firms might decide to adjust the margins in other products to recover the lost margins (Andia, 2018).

\section{Conclusions}

The price cap policy, using international price referencing to establish the maximum price of a pharmaceutical product, substantially reduced the prices of oral contraceptives in Colombia and triggered massive purchases by distributors. We observe a competitive response in products sharing an active ingredient, even if they were not directly regulated, but we do not observe a price response among products whose active ingredients were not regulated. Moreover, we interpret the null price response from non-regulated leaders, even after the drastic price reduction from their direct competitors within an active ingredient, as evidence of a strong vertical differentiation. Some products maintain relatively high prices, indicating that laboratories hold substantial market power.

The first year of this regulation seems to provide a net gain to final customers in the market, especially those who were loyal customers of the targeted brands, but also for more price-sensitive customers within the same active ingredient. However, for those customers of products belonging to non-regulated active ingredients (e.g., individuals using older contraceptive generations), there is no evidence of substitution. It remains unclear whether the policy will contribute to expand the usage of contraceptives, or at least to a faster uptake of newer (and safer) products. Questions in this direction could be answered with the integration of prescription data at the individual level.

From a methodological perspective, our combination of analyses at the wholesale and pharmacy level allowed us to show that, although the aggregate data revealed a price reduction and an expansion of traded quantities, the enhanced availability for final customers could not be taken for granted. Finally, we suggest a periodical review of the price-cap to avoid welfare losses coming from the firm's accommodation to this regulation (Abbott III, 1995; Moreno et al., 2017).

\section{References}

Abbott III, T. A. (1995). Price regulation in the pharmaceutical industry: Prescription or placebo? Journal of Health Economics, 14(5):551-565.

Acosta, A., Ciapponi, A., Aaserud, M., Vietto, V., Austvoll-Dahlgren, A., Kösters, J. P., Vacca, C., Machado, M., Ayala, D. H. D., and Oxman, A. D. (2014). Pharmaceutical policies: effects of reference pricing, other pricing, and purchasing policies. Cochrane Database of Systematic Reviews, (10).

Andia, T. (2018). El "efecto portafolio" de la regulación de precios de medicamentos: La re- 
spuesta de la industria farmacéutica a la regulación de precios de medicamentos en colombia". Washington, DC https:/ / doi. org/10.18235/0001305.

Andia, T., Mantilla, C., Morales, A., Ortiz, S., and Rodríguez, P. (2020). Extracting low-cost signals of quality control in community pharmacies: a simulated client study in Bogotá. Documentos de trabajo, Universidad del Rosario.

Balafoutas, L., Kerschbamer, R., and Sutter, M. (2015). Second-degree moral hazard in a real-world credence goods market. The Economic Journal, 127(599):1-18.

Bauhoff, S. (2012). Do health plans risk-select? an audit study on germany's social health insurance. Journal of Public Economics, 96(9-10):750-759.

Bitzer, J. (2015). Progestogens in contraception. In Carp, H., editor, Progestogens in Obstetrics and Gynecology, chapter 8, pages 111-128. Springer.

Brekke, K. R., Canta, C., and Straume, O. R. (2016). Reference pricing with endogenous generic entry. Journal of health economics, 50:312-329.

Costa-Font, J., McGuire, A., and Varol, N. (2014). Price regulation and relative delays in generic drug adoption. Journal of health economics, 38:1-9.

Currie, J., Lin, W., and Zhang, W. (2011). Patient knowledge and antibiotic abuse: Evidence from an audit study in china. Journal of Health Economics, 30(5):933-949.

Das, J., Holla, A., Mohpal, A., and Muralidharan, K. (2016). Quality and accountability in health care delivery: audit-study evidence from primary care in india. American Economic Review, 106(12):3765-99.

Das, J., Woskie, L., Rajbhandari, R., Abbasi, K., and Jha, A. (2018). Rethinking assumptions about delivery of healthcare: implications for universal health coverage. bmj, 361:k1716.

Frank, R. G. and Salkever, D. S. (1992). Pricing, patent loss and the market for pharmaceuticals. Southern Economic Journal, pages 165-179.

Guerrero, R., Prada, S., Pérez, A., Duarte, J., and Aguirre, A. (2015). Universal Health Coverage Assessment: Colombia. Technical report, Global Network for Health Equity.

Kwan, A., Daniels, B., Bergkvist, S., Das, V., Pai, M., and Das, J. (2019). Use of standardised patients for healthcare quality research in low-and middle-income countries. BMJ Global Health, 4(5):e001669.

List, J. A. (2004). The nature and extent of discrimination in the marketplace: Evidence from the field. Quarterly Journal of Economics, 119(1):49-89.

Madden, J. M., Quick, J. D., Ross-Degnan, D., and Kafle, K. K. (1997). Undercover careseekers: simulated clients in the study of health provider behavior in developing countries. Social Science \& Medicine, 45(10):1465-1482. 
Miller, R. and Goodman, C. (2016). Performance of retail pharmacies in low-and middle-income asian settings: a systematic review. Health policy and planning, 31(7):940-953.

Ministerio de Salud y Protección Social (2019). Boletín 03 - SISMED. Technical report, Ministerio de Salud y Protección Social, Bogotá, D.C.

Moreno, G., van Eijndhoven, E., Benner, J., and Sullivan, J. (2017). The long-term impact of price controls in medicare part $d$. In Forum for health economics \& policy, volume 20. De Gruyter.

Pan American Health Organization, United Nations Population Fund, and United Nations Children's Fund (2016). Accelerating progress toward the reduction of adolescent pregnancy in Latin America and the Caribbean. Technical report, Pan American Health Organization, Washington, D.C., USA.

Prada, S. I., Soto, V. E., Andia, T. S., Vaca, C. P., Morales, Á. A., Márquez, S. R., and Gaviria, A. (2018). Higher pharmaceutical public expenditure after direct price control: improved access or induced demand? the colombian case. Cost Effectiveness and Resource Allocation, 16(1):8.

Sitruk-Ware, R., Nath, A., and Mishell, D. (2012). Contraception technology: Past, present and future. Contraception, 87.

Smith, F. (2009). The quality of private pharmacy services in low and middle-income countries: a systematic review. Pharmacy world \& science, 31(3):351-361.

Sood, N., De Vries, H., Gutierrez, I., Lakdawalla, D. N., and Goldman, D. P. (2008). The effect of regulation on pharmaceutical revenues: Experience in nineteen countries: If the united states implemented price controls and negotiations similar to those in other developed countries, us revenues would fall by as much as 20.3 percent. Health Affairs, 27(Suppl1):w125-w137.

UNESCO (2017). Early and unintended pregnancy \& the education sector: Evidence review and recommendations. Technical report, UNESCO, Paris.

United Nations (2020). World Fertility 2019: Early and later childbearing among adolescent women. Technical report, United Nations, New York, NY.

Vacca, C., Nino, C., and Reveiz, L. (2011). Restriction of antibiotic sales in pharmacies in bogotá, colombia: a descriptive study. Revista Panamericana de Salud Pública, 30(6):586-591.

Von der Schulenburg, F., Vandoros, S., and Kanavos, P. (2011). The effects of drug market regulation on pharmaceutical prices in europe: overview and evidence from the market of ace inhibitors. Health economics review, 1(1):18.

Wafula, F. N., Miriti, E. M., and Goodman, C. A. (2012). Examining characteristics, knowledge and regulatory practices of specialized drug shops in sub-saharan africa: a systematic review of the literature. BMC health services research, 12(1):223. 
Watson, M. C., Norris, P., and Granas, A. (2006). A systematic review of the use of simulated patients and pharmacy practice research. International Journal of Pharmacy Practice, 14(2):8393.

Wiggins, S. N. and Maness, R. (2004). Price competition in pharmaceuticals: the case of antiinfectives. Economic Inquiry, 42(2):247-263.

World Health Organization (2011). Preventing Early Pregnancy and Poor Reproductive Outcomes Among Adolescents in Developing Countries. Technical report, World Health Organization, Geneva.

World Health Organization (2015). WHO Guideline on Country Pharmaceutical Pricing Policies. Technical report, World Health Organization, Geneva.

Zhang, W., Guh, D., Sun, H., Marra, C. A., Lynd, L. D., and Anis, A. H. (2016). The impact of price-cap regulations on exit by generic pharmaceutical firms. Medical care, 54(9):884-890. 


\section{A Appendix: Additional Tables and Figures}

Table A1: Characteristics of products within price ranges before the regulation

\begin{tabular}{|c|c|c|c|}
\hline \multirow[t]{2}{*}{ \# Products (CUM): 79} & \multicolumn{3}{|c|}{ Price Categories } \\
\hline & $\begin{aligned} & \text { Bottom } \\
& \leq 18,000\end{aligned}$ & $\begin{array}{c}\text { Intermediate } \\
(18,000 ; 49,000]\end{array}$ & $\begin{aligned} & \text { Top } \\
> & 49,000\end{aligned}$ \\
\hline Commercial description (Brands) & $20 / 79$ & $40 / 79$ & $19 / 79$ \\
\hline Active ingredients (ATC code) & 6 & 14 & 6 \\
\hline Laboratories & 13 & 12 & 6 \\
\hline Average price (USD) & 3.43 & 10.41 & 17.52 \\
\hline Average price with respect to benchmark & 0.27 & 0.82 & 1.37 \\
\hline Fourth generation (\%) & 5 & 55 & 52.6 \\
\hline Quarters since the product started to be active & 37.6 & 33.3 & 32.7 \\
\hline Quarters since the register was issued & 58.4 & 43.4 & 45.8 \\
\hline Market share units (\%) & 54.95 & 27.34 & 17.69 \\
\hline Market share sales value (\%) & 18.5 & 37.77 & 43.72 \\
\hline $\mathrm{HHI}$ & 2348.12 & 1860.18 & 4019.47 \\
\hline HHI sales value & 1986.47 & 1814.45 & 3888.36 \\
\hline Regulated brands (\%) & 20 & 37.5 & 52.6 \\
\hline Regulated units (\%) & 32.65 & 78.63 & 86.18 \\
\hline Regulated sales value (\%) & 34.64 & 75.44 & 85.19 \\
\hline
\end{tabular}

Notes: Calculations based on administrative data records from SISMED including all oral contraceptives with registered transactions at least every year (2017-2019). For this analysis, we used data from periods before regulation. In the computations of the Herfindahl-Hirschman Index (HHI) we assumed three markets, one per price level. We aggregated sales and sales value by manufacturer (laboratory) in each market. Quarters Active and Quarters Issued are the average difference between the active and issued date, with respect to 2019Q1. Benchmark value is 41,908 COP, corresponding to US $\$ 12.69$ according to an average exchange rate of 3,300 COP/USD between 2018Q4 and 2019Q1. The benchmark value corresponds to the average price of low-end audited brands (Dienille and Drospera) before regulation. Products are defined by their unique combination of drug name, dosage, and presentation (CUM code). 
Table A2: Regulation effects by price category. Replication of Table 3 using different thresholds for the price categories.

\begin{tabular}{|c|c|c|c|c|c|c|}
\hline & $\begin{array}{c}(1) \\
\text { Relative price }\end{array}$ & $\begin{array}{c}(2) \\
\operatorname{Ln}(\text { Quantity) }\end{array}$ & $\begin{array}{c}\text { (3) } \\
\text { Relative price }\end{array}$ & $\begin{array}{c}(4) \\
\text { Ln(Quantity) }\end{array}$ & $\begin{array}{c}\text { (5) } \\
\text { Relative price }\end{array}$ & $\begin{array}{c}\text { (6) } \\
\operatorname{Ln}(\text { Quantity) }\end{array}$ \\
\hline Top $\times$ Non-regulated $\times$ After & $\begin{array}{l}-0.0395 \\
(0.0421)\end{array}$ & $\begin{array}{c}-0.405^{* *} \\
(0.192)\end{array}$ & $\begin{array}{l}-0.0385 \\
(0.0421)\end{array}$ & $\begin{array}{c}-0.406^{* * *} \\
(0.192)\end{array}$ & $\begin{array}{l}-0.0129 \\
(0.0412)\end{array}$ & $\begin{array}{c}-0.452^{* * *} \\
(0.187)\end{array}$ \\
\hline Top $\times$ Reg. Ingredient $\times$ After & $\begin{array}{l}-0.463^{*} \\
(0.274)\end{array}$ & $\begin{array}{c}0.347 \\
(0.396)\end{array}$ & $\begin{array}{l}-0.463^{*} \\
(0.274)\end{array}$ & $\begin{array}{c}0.346 \\
(0.396)\end{array}$ & $\begin{array}{c}-0.375^{* *} \\
(0.170)\end{array}$ & $\begin{array}{l}0.0304 \\
(0.318)\end{array}$ \\
\hline Top $\times$ Reg. Product $\times$ After & $\begin{array}{c}-0.951^{* * *} \\
(0.0552)\end{array}$ & $\begin{array}{c}0.225 \\
(0.187)\end{array}$ & $\begin{array}{c}-0.949^{* * *} \\
(0.0551)\end{array}$ & $\begin{array}{c}0.225 \\
(0.187)\end{array}$ & $\begin{array}{c}-0.851^{* * *} \\
(0.0743)\end{array}$ & $\begin{array}{c}0.149 \\
(0.309)\end{array}$ \\
\hline Interm. $\times$ Non-regulated $\times$ After & $\begin{array}{l}-0.0537 \\
(0.0453)\end{array}$ & $\begin{array}{c}-0.418^{* *} \\
(0.176)\end{array}$ & $\begin{array}{l}-0.0582 \\
(0.0421)\end{array}$ & $\begin{array}{c}-0.327^{* *} \\
(0.156)\end{array}$ & $\begin{array}{l}-0.0724^{*} \\
(0.0427)\end{array}$ & $\begin{array}{l}-0.257 \\
(0.158)\end{array}$ \\
\hline Interm. $\times$ Reg. Ingredient $\times$ After & $\begin{array}{c}-0.487^{* * *} \\
(0.101)\end{array}$ & $\begin{array}{c}0.477 \\
(0.340)\end{array}$ & $\begin{array}{c}-0.439^{* * *} \\
(0.109)\end{array}$ & $\begin{array}{c}0.441 \\
(0.312)\end{array}$ & $\begin{array}{c}-0.515^{* * *} \\
(0.129)\end{array}$ & $\begin{array}{l}0.787^{* *} \\
(0.358)\end{array}$ \\
\hline Interm. $\times$ Reg. Product $\times$ After & $\begin{array}{c}-0.682^{* * *} \\
(0.0794)\end{array}$ & $\begin{array}{c}0.120 \\
(0.280)\end{array}$ & $\begin{array}{c}-0.577^{* * *} \\
(0.0610)\end{array}$ & $\begin{array}{c}0.191 \\
(0.180)\end{array}$ & $\begin{array}{c}-0.433^{* * *} \\
(0.0374)\end{array}$ & $\begin{array}{l}0.225^{* *} \\
(0.110)\end{array}$ \\
\hline Bottom $\times$ Non-regulated $\times$ After & $\begin{array}{l}-0.0327 \\
(0.0268)\end{array}$ & $\begin{array}{c}-0.219^{* *} \\
(0.107)\end{array}$ & $\begin{array}{l}-0.0380 \\
(0.0267)\end{array}$ & $\begin{array}{c}-0.289^{* *} \\
(0.141)\end{array}$ & $\begin{array}{l}-0.0366 \\
(0.0269)\end{array}$ & $\begin{array}{c}-0.299^{* *} \\
(0.146)\end{array}$ \\
\hline Bottom $\times$ Reg. Ingredient $\times$ After & $\begin{array}{l}-0.0700 \\
(0.0444)\end{array}$ & $\begin{array}{c}0.00635 \\
(0.102)\end{array}$ & $\begin{array}{l}-0.0611 \\
(0.0503)\end{array}$ & $\begin{array}{r}-0.0201 \\
(0.119)\end{array}$ & $\begin{array}{l}-0.0598 \\
(0.0503)\end{array}$ & $\begin{array}{r}-0.0297 \\
(0.123)\end{array}$ \\
\hline Bottom $\times$ Reg. Product $\times$ After & $\begin{array}{c}-0.369^{* * *} \\
(0.0347)\end{array}$ & $\begin{array}{l}0.286^{*} \\
(0.151)\end{array}$ & $\begin{array}{c}-0.272^{* * *} \\
(0.0372)\end{array}$ & $\begin{array}{c}0.223 \\
(0.256)\end{array}$ & $\begin{array}{c}-0.260^{* * *} \\
(0.0447)\end{array}$ & $\begin{array}{c}0.250 \\
(0.295)\end{array}$ \\
\hline Constant & $\begin{array}{l}0.780^{* * *} \\
(0.0347)\end{array}$ & $\begin{array}{c}9.047^{* * *} \\
(0.132)\end{array}$ & $\begin{array}{l}0.779^{* * *} \\
(0.0361)\end{array}$ & $\begin{array}{c}9.051^{* * *} \\
(0.135)\end{array}$ & $\begin{array}{l}0.778^{* * *} \\
(0.0356)\end{array}$ & $\begin{array}{c}9.052^{* * *} \\
(0.132)\end{array}$ \\
\hline Observations & 551 & 551 & 551 & 551 & 551 & 551 \\
\hline Number of drugs & 52 & 52 & 52 & 52 & 52 & 52 \\
\hline R-squared & 0.740 & 0.119 & 0.699 & 0.099 & 0.742 & 0.122 \\
\hline Adjusted R-squared & 0.733 & 0.094 & 0.691 & 0.073 & 0.735 & 0.097 \\
\hline $\begin{array}{l}\text { Bottom } \\
\text { Intermediate } \\
\text { Top }\end{array}$ & \multicolumn{2}{|c|}{$\begin{array}{c}\leq 28,000 \\
(28,000 ; 53,000] \\
>53,000\end{array}$} & \multicolumn{2}{|c|}{$\begin{array}{c}\leq 22,000 \\
(22,000 ; 53,000] \\
>53,000\end{array}$} & \multicolumn{2}{|c|}{$\begin{array}{c}\leq 21,000 \\
(21,000 ; 47,000] \\
>47,000\end{array}$} \\
\hline
\end{tabular}


Table A3: Regulation effects by price category taking each progestin-estrogen classification as a different active ingredient.

\begin{tabular}{|c|c|c|c|c|}
\hline & $\begin{array}{l}\text { (1) } \\
\text { Relative price }\end{array}$ & $\begin{array}{l}\text { (2) } \\
\text { Relative price }\end{array}$ & $\begin{array}{c}\text { (3) } \\
\text { Ln(Quantity) }\end{array}$ & $\begin{array}{c}(4) \\
\operatorname{Ln}(Q u a n t i t y)\end{array}$ \\
\hline Top $\times$ After & $\begin{array}{c}-0.490^{* * *} \\
(0.140)\end{array}$ & & $\begin{array}{l}-0.0115 \\
(0.244)\end{array}$ & \\
\hline Interm. $\times$ After & $\begin{array}{c}-0.364^{* * *} \\
(0.0502)\end{array}$ & & $\begin{array}{c}0.186 \\
(0.124)\end{array}$ & \\
\hline Bottom $\times$ After & $\begin{array}{c}-0.0858^{* *} \\
(0.0345)\end{array}$ & & $\begin{array}{l}-0.0797 \\
(0.215)\end{array}$ & \\
\hline Top $\times$ Non-regulated $\times$ After & & $\begin{array}{l}-0.120^{* *} \\
(0.0545)\end{array}$ & & $\begin{array}{c}-0.389^{* *} \\
(0.159)\end{array}$ \\
\hline Top $\times$ Reg. Ingredient $\times$ After & & $\begin{array}{l}-0.449 \\
(0.326)\end{array}$ & & $\begin{array}{l}0.0687 \\
(0.596)\end{array}$ \\
\hline Top $\times$ Reg. Product $\times$ After & & $\begin{array}{c}-0.998^{* * *} \\
(0.0431)\end{array}$ & & $\begin{array}{c}0.416^{* * *} \\
(0.230)\end{array}$ \\
\hline Interm. $\times$ Non-regulated $\times$ After & & $\begin{array}{l}-0.0396 \\
(0.0379)\end{array}$ & & $\begin{array}{l}-0.255^{*} \\
(0.128)\end{array}$ \\
\hline Interm. $\times$ Reg. Ingredient $\times$ After & & $\begin{array}{l}-0.630^{* * *} \\
(0.0626)\end{array}$ & & $\begin{array}{c}0.936^{* * *} \\
(0.286)\end{array}$ \\
\hline Interm. $\times$ Reg. Product $\times$ After & & $\begin{array}{l}-0.465^{* * *} \\
(0.0362)\end{array}$ & & $\begin{array}{c}0.189 \\
(0.152)\end{array}$ \\
\hline Bottom $\times$ Non-regulated $\times$ After & & $\begin{array}{l}-0.0333 \\
(0.0276)\end{array}$ & & $\begin{array}{l}-0.299^{*} \\
(0.164)\end{array}$ \\
\hline Bottom $\times$ Reg. Ingredient $\times$ After & & $\begin{array}{l}-0.0763 \\
(0.0573)\end{array}$ & & $\begin{array}{l}-0.0228 \\
(0.150)\end{array}$ \\
\hline Bottom $\times$ Reg. Product $\times$ After & & $\begin{array}{c}-0.173^{* * *} \\
(0.0157)\end{array}$ & & $\begin{array}{l}0.0726 \\
(0.480)\end{array}$ \\
\hline Constant & $\begin{array}{l}0.777^{* * *} \\
(0.0367)\end{array}$ & $\begin{array}{l}0.780^{* * *} \\
(0.0335)\end{array}$ & $\begin{array}{c}9.059^{* * *} \\
(0.133)\end{array}$ & $\begin{array}{c}9.047^{* * *} \\
(0.130)\end{array}$ \\
\hline Observations & 551 & 551 & 551 & 551 \\
\hline Number of drugs & 52 & 52 & 52 & 52 \\
\hline R-squared & 0.496 & 0.775 & 0.029 & 0.163 \\
\hline Adjusted R-squared & 0.488 & 0.769 & 0.013 & 0.139 \\
\hline
\end{tabular}

Notes: Regressions based on 52 drugs for which there are registered transactions at least every year in the period of analysis from 2017Q1 to 2019Q3. All regressions include a price-level specific linear trend, quarter seasonal dummies, and drug fixed effects. Products are defined by their unique combination of drug name, dosage, and presentation (CUM code). Drugs are aggregated by the exact active ingredient (progestin-estrogen), that is, a unique ATC code. Clustered standard errors by drug-level are shown in parentheses. Significance: ${ }^{*} \mathrm{p}<0.1{ }^{* *} \mathrm{p}<0.05 ;{ }^{* * *} \mathrm{p}<0.01$. 
Table A4: Regulation effects by price category at wholesale level - 79 drugs sample

\begin{tabular}{|c|c|c|c|c|}
\hline & $\begin{array}{c}\text { (1) } \\
\text { Relative price }\end{array}$ & $\begin{array}{c}(2) \\
\text { Relative price }\end{array}$ & $\begin{array}{c}(3) \\
\operatorname{Ln}(Q u a n t i t y)\end{array}$ & $\begin{array}{c}(4) \\
\operatorname{Ln}(Q u a n t i t y)\end{array}$ \\
\hline Top $\times$ After & $\begin{array}{c}-0.454^{* * *} \\
(0.135)\end{array}$ & & $\begin{array}{l}0.0712 \\
(0.234)\end{array}$ & \\
\hline Interm. $\times$ After & $\begin{array}{c}-0.358^{* * *} \\
(0.0495)\end{array}$ & & $\begin{array}{c}0.196 \\
(0.118)\end{array}$ & \\
\hline Bottom $\times$ After & $\begin{array}{c}-0.0725^{* *} \\
(0.0302)\end{array}$ & & $\begin{array}{l}-0.102 \\
(0.198)\end{array}$ & \\
\hline Top $\times$ Non-regulated $\times$ After & & $\begin{array}{l}-0.0544^{*} \\
(0.0307)\end{array}$ & & $\begin{array}{c}-0.0387 \\
(0.217)\end{array}$ \\
\hline Top $\times$ Reg. Ingredient $\times$ After & & $\begin{array}{l}-0.283 \\
(0.173)\end{array}$ & & $\begin{array}{l}-0.155 \\
(0.342)\end{array}$ \\
\hline Top $\times$ Reg. Product $\times$ After & & $\begin{array}{c}-0.999 * * * \\
(0.0472)\end{array}$ & & $\begin{array}{l}0.501^{* *} \\
(0.231)\end{array}$ \\
\hline Interm. $\times$ Non-regulated $\times$ After & & $\begin{array}{c}-0.0641 \\
(0.0465)\end{array}$ & & $\begin{array}{l}-0.141 \\
(0.193)\end{array}$ \\
\hline Interm. $\times$ Reg. Ingredient $\times$ After & & $\begin{array}{c}-0.415^{* * *} \\
(0.112)\end{array}$ & & $\begin{array}{c}0.498^{*} \\
(0.259)\end{array}$ \\
\hline Interm. $\times$ Reg. Product $\times$ After & & $\begin{array}{c}-0.470^{* * *} \\
(0.0363)\end{array}$ & & $\begin{array}{c}0.189 \\
(0.150)\end{array}$ \\
\hline Bottom $\times$ Non-regulated $\times$ After & & $\begin{array}{l}-0.0275 \\
(0.0271)\end{array}$ & & $\begin{array}{l}-0.279^{*} \\
(0.158)\end{array}$ \\
\hline Bottom $\times$ Reg. Ingredient $\times$ After & & $\begin{array}{l}-0.0618 \\
(0.0459)\end{array}$ & & $\begin{array}{c}-0.0881 \\
(0.167)\end{array}$ \\
\hline Bottom $\times$ Reg. Product $\times$ After & & $\begin{array}{c}-0.167^{* * *} \\
(0.0167)\end{array}$ & & $\begin{array}{l}0.0951 \\
(0.461)\end{array}$ \\
\hline Constant & $\begin{array}{l}0.777^{* * *} \\
(0.0356)\end{array}$ & $\begin{array}{l}0.760^{* * *} \\
(0.0335)\end{array}$ & $\begin{array}{c}8.741^{* * *} \\
(0.126)\end{array}$ & $\begin{array}{c}8.748^{* * *} \\
(0.128)\end{array}$ \\
\hline Observations & 650 & 650 & 650 & 650 \\
\hline Number of drugs & 79 & 79 & 79 & 79 \\
\hline R-squared & 0.478 & 0.693 & 0.028 & 0.069 \\
\hline Adjusted R-squared & 0.471 & 0.685 & 0.015 & 0.047 \\
\hline
\end{tabular}

Notes: Regressions based on 79 drugs for which there are registered at least one transaction in the period of analysis from 2017Q1 to 2018Q4. All regressions include a price-level specific linear trend, quarter seasonal dummies, and drug fixed effects. Products are defined by their unique combination of drug name, dosage, and presentation (CUM code). We aggregated medications by the progestin used as active ingredient. Clustered standard errors by drug-level are shown in parentheses. Significance: ${ }^{*} \mathrm{p}<0.1$; ${ }^{* *} \mathrm{p}<0.05 ;{ }^{* * *} \mathrm{p}<0.01$. 
Figure A1: Distribution of prices in 2018Q4, 56 products

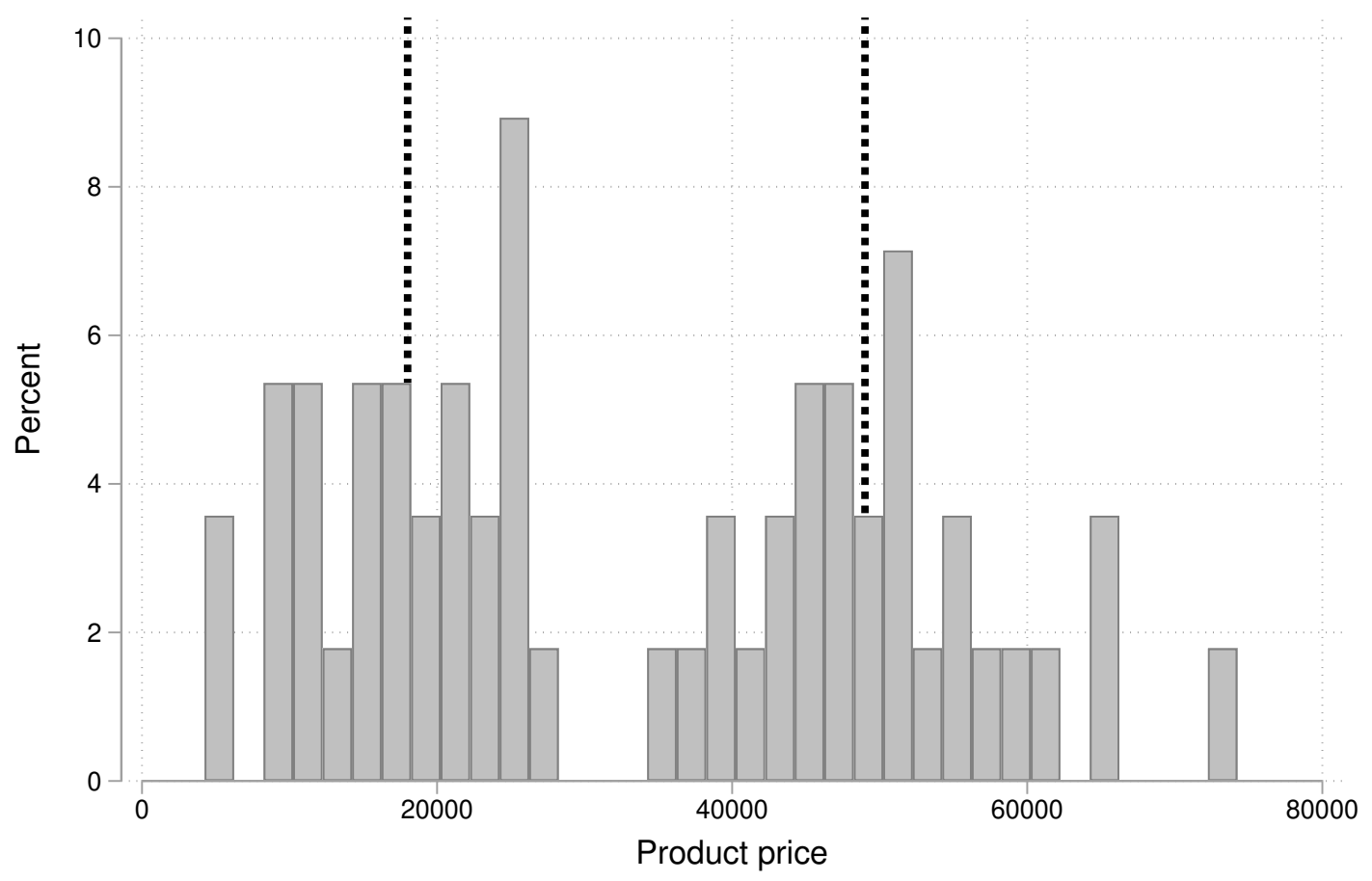

Vertical lines: 18.000 COP and 49.000 COP, the limits of the Bottom, Intermediate, and Top price categories. 
Figure A2: Prices before and after the regulation registered in SISMED - (progestin-estrogen)

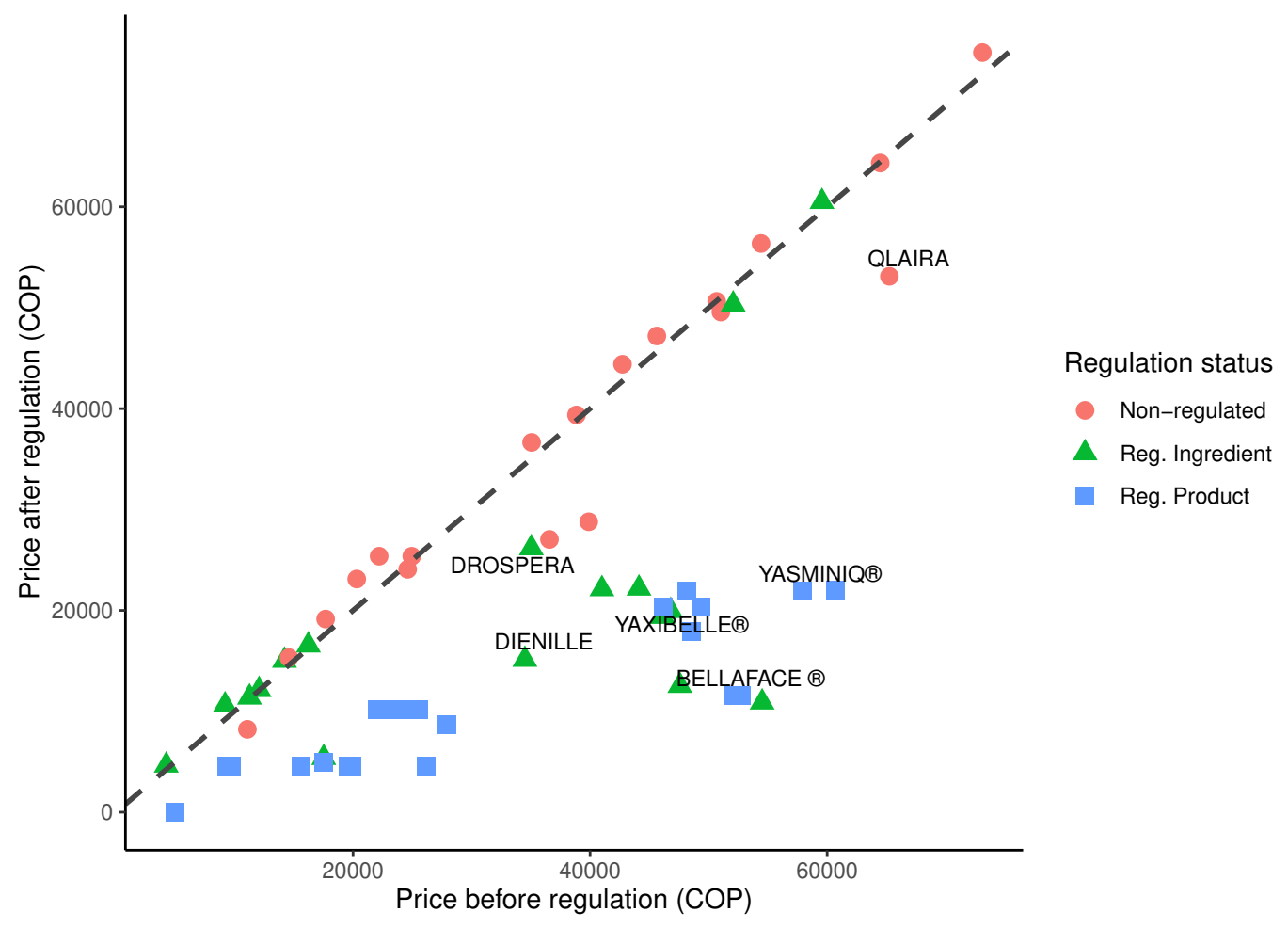

Note: Blue squares correspond to the regulated products, green triangles to regulated ingredients, and red circles to the non-regulated products. Products are defined by their unique combination of the drug name, dosage, and presentation (CUM code). We aggregated medications by the progestin they use as an active ingredient. Calculations are based on administrative data records from SISMED. We included 56 oral contraceptives brands that reported prices at least in one period both before and after regulation. Drospera and Dienille were only published in one period in our period of analysis, and therefore, we imputed their prices from the public SISMED database. The "before regulation" period goes from 2017Q1 to 2018Q4, and the "after regulation" period goes from 2019Q1 onward. 
Figure A3: Yasminiq x After regulation

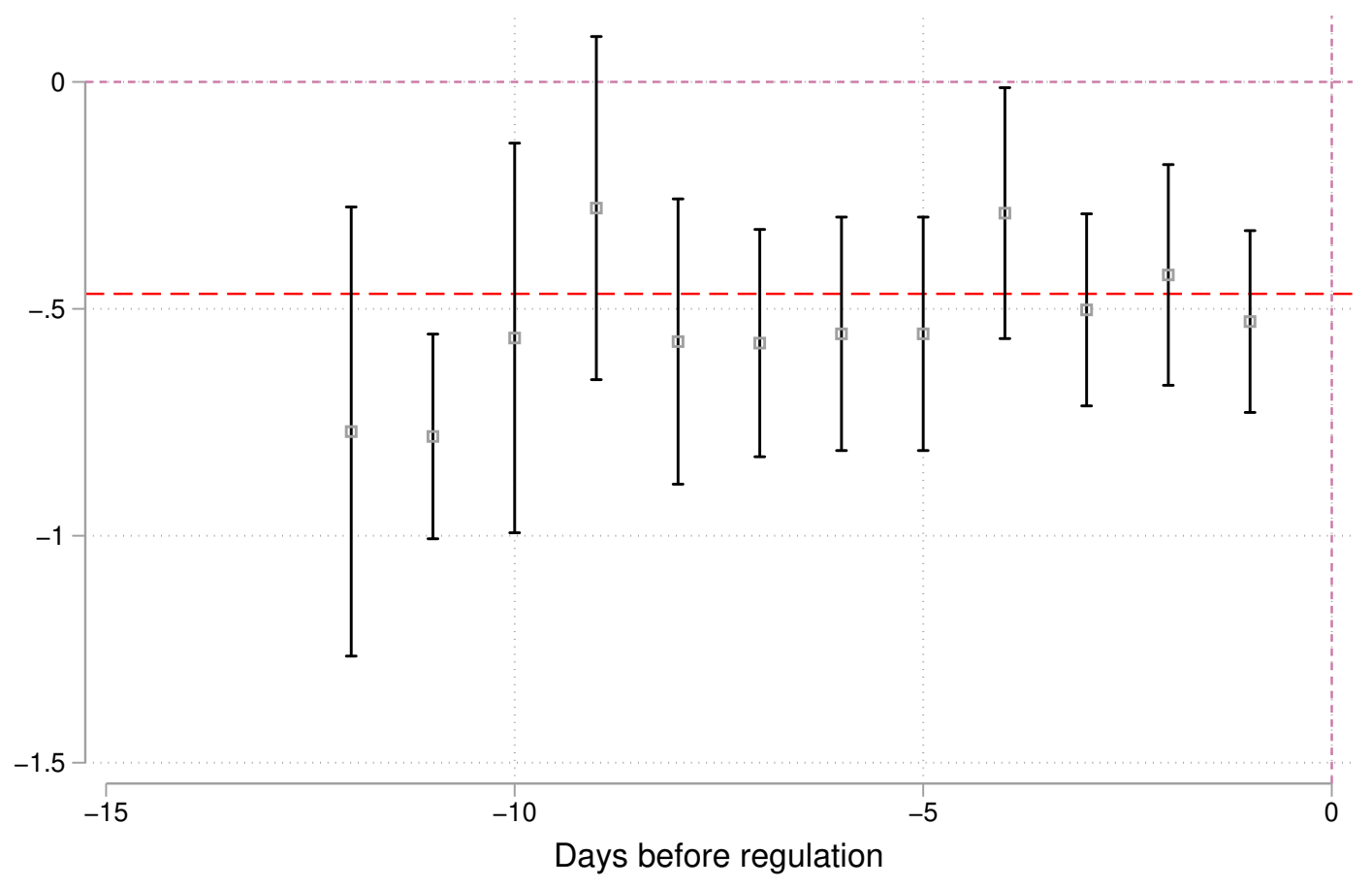


Figure A4: Availability of high-end contraceptives in the city according to socioeconomic level

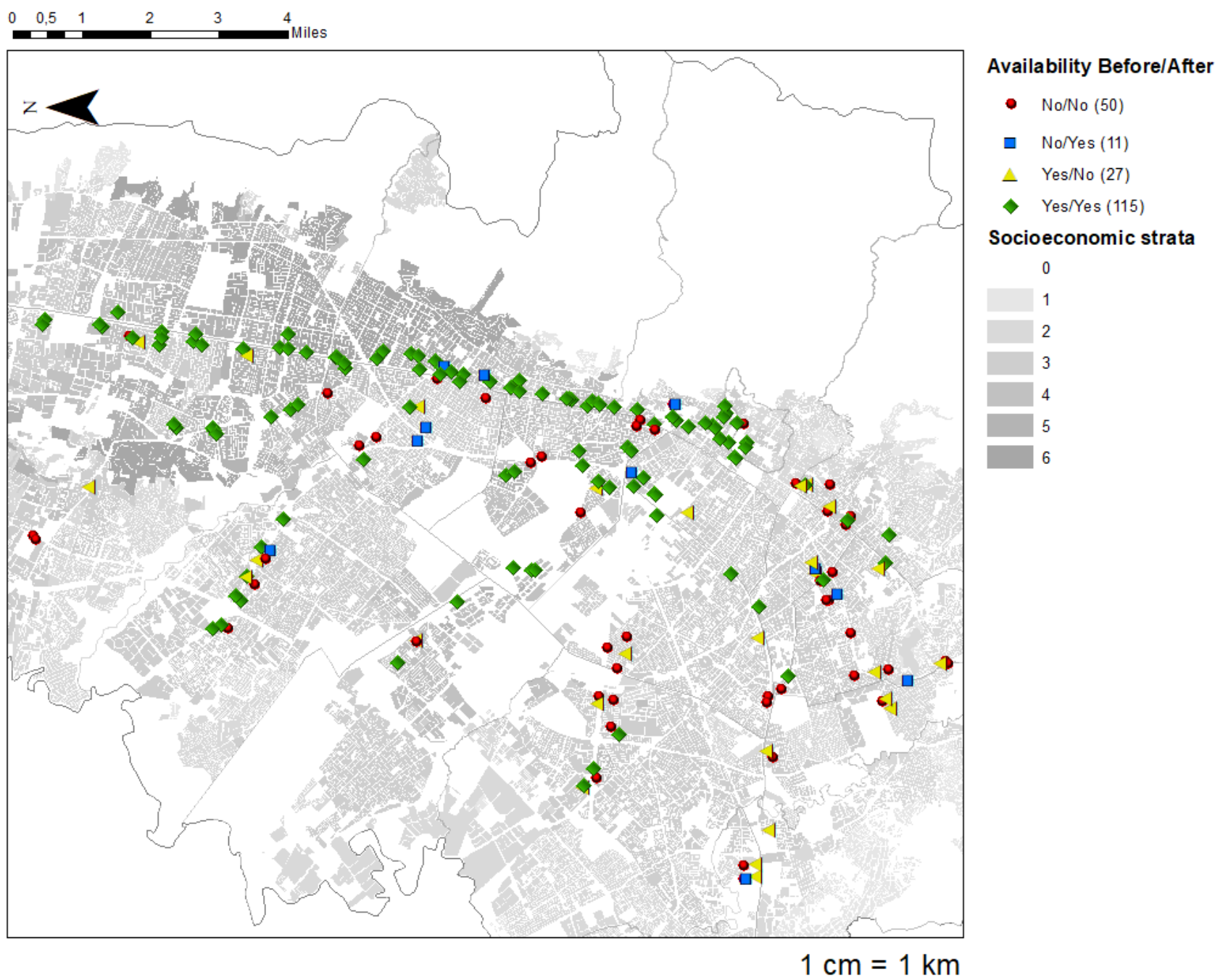

Note: Own calculations based on community pharmacies that were visited or called at least twice. 
Figure A5: Availability of low-end contraceptives in the city according to socioeconomic level

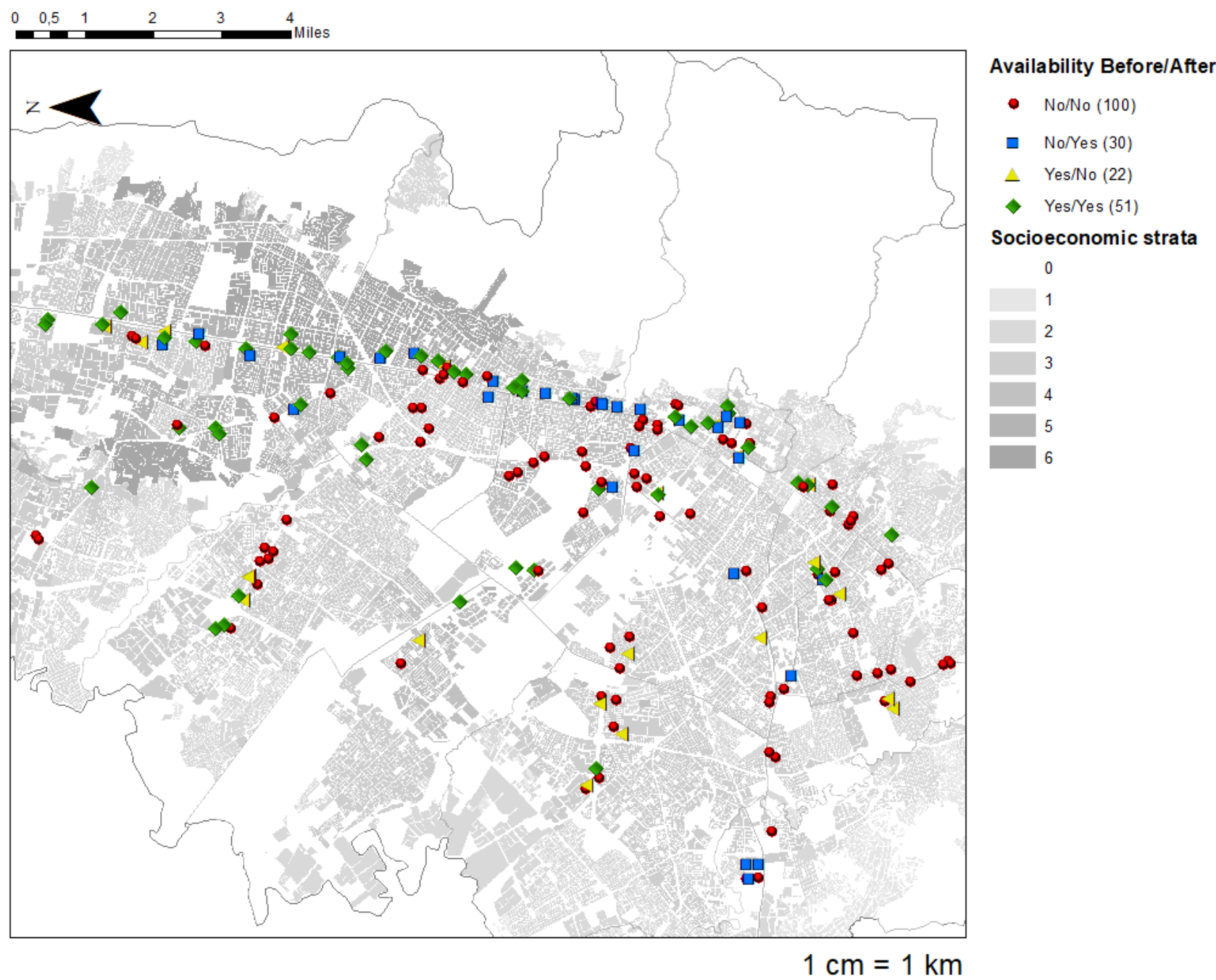

Note: Own calculations based on community pharmacies that were visited or called at least twice. 